OPEN ACCESS

Edited by: Maria Rosaria De Miglio, University of Sassari, Italy

Reviewed by: Yizi Cong,

Yantai Yuhuangding Hospital, China Alessandra Gennari, Università del Piemonte Orientale, Italy

*Correspondence: Li-bin Wang wanglibin007@126.com Li-gang Wu

wuligang654321@163.com

${ }^{t}$ These authors have contributed equally to this work

Specialty section: This article was submitted to Breast Cancer, a section of the journal Frontiers in Oncology

Received: 29 April 2021 Accepted: 17 August 2021 Published: 13 September 2021

Citation:

Tian J-h, Liu S-h, Yu C-y, Wu L-g and Wang L-b (2021) The Role of Non-Coding RNAs in Breast Cancer Drug Resistance.

Front. Oncol. 11:702082. doi: 10.3389/fonc.2021.702082

\section{The Role of Non-Coding RNAs in Breast Cancer Drug Resistance}

\author{
Jin-hai Tian ${ }^{1,2 \dagger}$, Shi-hai $\mathrm{Liu}^{3 \dagger}$, Chuan-yang $\mathrm{Yu}^{1,2}$, Li-gang $\mathrm{Wu}^{4 *}$ and Li-bin Wang ${ }^{1,2 *}$ \\ 1 The Biochip Research Center, General Hospital of Ningxia Medical University, Yinchuan, China, Yinchuan, China, 2 The Clinical \\ Medicine College of Ningxia Medical University, Yinchuan, China, ${ }^{3}$ Medical Research Center, The Affiliated Hospital of Qingdao \\ University, Qingdao, China, ${ }^{4}$ Department of Oncology, General Hospital of Ningxia Medical University, Yingchuan, China
}

Breast cancer $(\mathrm{BC})$ is one of the commonly occurring malignancies in females worldwide. Despite significant advances in therapeutics, the mortality and morbidity of BC still lead to low survival and poor prognosis due to the drug resistance. There are certain chemotherapeutic, endocrine, and target medicines often used for BC patients, including anthracyclines, taxanes, docetaxel, cisplatin, and fluorouracil. The drug resistance mechanisms of these medicines are complicated and have not been fully elucidated. It was reported that non-coding RNAs (ncRNAs), such as micro RNAs (miRNA), long-chain non-coding RNAs (IncRNAs), and circular RNAs (circRNAs) performed key roles in regulating tumor development and mediating therapy resistance. However, the mechanism of these ncRNAs in BC chemotherapeutic, endocrine, and targeted drug resistance was different. This review aims to reveal the mechanism and potential functions of ncRNAs in BC drug resistance and to highlight the ncRNAs as a novel target for achieving improved treatment outcomes for BC patients.

Keywords: breast cancer, drug resistance, non-coding RNA, micro RNA, long-chain non-coding RNA

\section{INTRODUCTION}

Breast cancer (BC), a complicated and heterogeneous disease which has high metastasis and recurrence rate, is a diverse hormone-dependent malignancy carcinoma and is leading in cancer mortality and morbidity globally. More than 20 million BC patients are newly diagnosed in women worldwide (1). Because of the heterogeneity of $\mathrm{BC}$, drug resistance has become one of the major challenges. Although certain advances in research have been applied, the drug resistance of BC is still responsible for the poor prognosis and quite low survival (2). There are certain chemotherapeutic, endocrine, and targeted drugs available which have significantly improved the life quality and overall survival of patients, including anthracyclines, taxanes, cisplatin, and fluorouracil. For these therapeutic drugs, the mechanisms of drug resistance are complicated and have not been fully elucidated.

Non-coding RNAs (ncRNAs), including microRNAs (miRNAs), long-chain non-coding RNAs (LncRNAs), piRNAs, and circle RNAs (circRNAs), a group of RNAs which lack protein-coding regions, only account for about $1 \%$ of total genome RNA (3). Although these ncRNAs are less abundant, they exhibited essential performance in transcription, posttranscription, translation, and regulation of cellular processes and signaling pathways in the development and pathology of 
different cancer cells $(4,5)$. Besides, ncRNAs also have a significant influence on the exon gene coding via a different mechanism. The ability of ncRNAs to control gene expression makes them as targets or the key regulating genes for the tumor drug resistance (6).

Previous research reported that ncRNAs have the ability to modulate the sensitivity of cancer cell therapy. This ability contributed to the cancer cell drug resistance acquisition. This review summarizes the possible roles of ncRNAs in drug resistance following different mechanisms, highlighting the therapeutic and diagnostic application of ncRNAs for overcoming the $\mathrm{BC}$ resistance.

\section{NCRNAS AND ANTHRACYCLINE CHEMORESISTANCE}

Anthracyclines are a group of antibiotics that are among the most active chemotherapeutic agents. The commonly used anthracycline antibiotics include doxorubicin, daunorubicin, and epirubicin (7). Anthracyclines exhibited a critical role in treating BC and can be used at all BC stages (8). Unfortunately, these agents also exhibited a well-recognized cardiotoxic profile that limits its clinical application (9). Several studies reported the mechanism of the chemoresistance of anthracycline and showed that ncRNAs exhibited high possibility in regulating $\mathrm{BC}$ resistance.

\section{miRNA and Anthracycline Chemoresistance}

Chen et al. (10) found that the expression of miR-200c was related to doxorubicin-resistant BC. Upregulation of miR-200c could improve the epirubicin chemoselectivity and is also capable of decreasing the expression of P-glycoprotein (P-gp) and multidrug resistance mRNA in the human MCF-7/ADR cell line. Kopp et al. (11) found that decreased miR-200c expression in doxorubicin-resistant epithelial BC cell line BT474 could make the cells display the mesenchymal cell characteristics. Inhibition and overexpression miR-200c in the cells enhanced its resistance to doxorubicin treatment. Li et al. (12) and Park et al. (13) reported that miR-34a was down-expressed in MCF-7/ADR cells as compared to MCF-7 cells. Overexpression of miR-34a could increase the sensitivity of MCF-7/ADR cells to doxorubicin treatment by targeting NOTCH1. Zheng et al. (14) found that miR-181b performed the function of oncogenes during the development of BC and chemoresistance. Zhao et al. (15) found that downregulation of the miR-302S family genes miR302d, miR-302c, miR-302b, and miR-302a could increase P-gp expression and enhance the chemoresistance of MCF-7/ADR cells. The enhanced expression of miR-302 facilitated the ADM agglomeration at extracellular and increased the sensitivity of BC cells for ADM. Spindlin1 (SPIN1) is an extremely expressed protein in various cancer types and is also associated with tumor development and genesis. Chen et al. (16) found that SPIN1 was a novel target of the miR-148/152 family; upregulation of miR148/152 inhibited the SPIN1 expression and induced UGT2B4,
CYP2C8, UGT2B17, and $\mathrm{ABCB} 4$ increase. The increase of UGT2B4, CYP2C8, UGT2B17, and ABCB4 is thereby involved in drug metabolism and transport along with enhancement in $\mathrm{ADM}$ resistance in $\mathrm{BC}$. $\mathrm{Hu}$ et al. (17) reported the abrupt expression of ABCC4 and miR-124-3p in BC and MCF-7/ADR cells. After inhibiting the expression of ABCC4 and miR-124-3p, the sensitivity of the cells toward ADM was significantly increased. Doxorubicin was located in the cytoplasm rather than the nuclei of resistant cells due to the increased nuclear expression of MDR1/P-gp. Bao et al. (18) found that overexpression of miR-298 could inhibit P-gp and increase the $\mathrm{P}$-gp nuclear accumulation and cytotoxicity in doxorubicinresistant BC cells. The results suggested that miR-298 directly affects P-gp expression and influenced metastatic BC chemoresistance. Shen et al. (19) reported that miR-29a could play an important role in $\mathrm{ADM}$ resistance by inhibiting the PTEN/AKT/GSK3 $\beta$ signaling pathway in BC cells.

Miao et al. (20) revealed that miR-130b induced BC cell chemoresistance and promoted its proliferation through targeting PTEN and PI3K/Akt signaling pathway. Besides, the Wang group showed that miR-222 was capable of decreasing the sensitivity of BC cells to ADM through the PTEN/Akt/p27kip1 signaling pathway (21). The major cause of chemoresistance in $\mathrm{BC}$ was the overexpression of multidrug resistance-associated protein 1 (MRP1). Gao et al. (22) found that miR-145 could directly target MRP1 3'-untranslated regions and suppression of MRP1 expression. Overexpression of miR-145 could inhibit MRP1 expression and improve the extracellular doxorubicin accumulation. Jiang et al. (23) illustrated that the EMT-related chemoresistance in BC cells was mediated by miR-489. In their report, the EMT features and chemoresistance of ADM resistance cells (MCF-7/ $\mathrm{ADM}$ ) were reversed by overexpression of miR-489 through targeting Smad3. Meanwhile, $\mathrm{Hu}$ et al. (24) observed that overexpression of miR-760 increased the sensitivity of BC cells for certain anticancer agents via improved EMT transfer. The results proved that miR-760 was capable of modulating the chemoresistance of BC cells through EMT. Zhang et al. (25) explored the role of miRNA-192-5p in doxorubicin-resistant BC cells. They found that miR-192-5p overexpression was capable of activating JNK, augmenting Bad and caspase9, and suppressing the expression of Bcl-2 and PPIA. Zhao et al. (26) reported the correlation between miR-221 expression and the status of the hormone receptor (HR). In the research, they found that the patients with an increased miR-221 level in the plasma were considered to be HR-negative, and miR-221 can be a biomarker for evaluating the sensitivity of BC patients who previously received neoadjuvant chemotherapy.

\section{LncRNAs in Anthracycline Chemoresistance}

LncRNAs comprise a group of over 200 nucleotides containing non-coding RNA molecules, while microRNAs include almost 21 nucleotides containing non-coding regulatory transcripts. It was reported that lncRNAs are involved in various drug resistance- and carcinogenesis-related genomics and cellular processes. The significance of lncRNAs was also discussed in the $\mathrm{BC}$ resistance against multiple drugs. For example, the 
expression of lnc00518 and multidrug resistance protein 1 (MRP1) was observed in MDR breast cells (MCF-7/ADR) compared with the normal MCF-7 line (27). Inc00518 was capable of reducing the apoptosis through inhibiting the miR199a/MRP1 axis and increasing the resistance of MCF-7/ADR cells to VCR and ADM. Liang et al. (28) suggested that overexpression of IncLINP1 was positively related to the proliferation, chemoresistance, and metastasis of BC cells. Knockdown of LINP1 promoted BC cell metastasis and increased its resistance to 5-Fu by decreasing the effects of P53. Yao et al. (29) found that lncRNA NONHSAT101069 acted as ceRNA with miR-129-5p and targeted Twist1 in BC cells. The expression of IncRNA NONHSAT101069 promoted the resistance of $\mathrm{BC}$ cells to epirubicin and induced the cell EMT and migration process through the lncRNA NONHSAT101069/ miR-129-5p/Twist1 axis. Gooding et al. (30) reported that lncRNABORG promoted the triple-negative BC (TNBC) cell chemoresistance to doxorubicin by activating the NF- $\kappa \mathrm{B}$ signaling pathway. Chen et al. (31) found that LncRNAGAS5 significantly reversed the $\mathrm{BC}$ cell drug resistance by suppressing the Wnt/ $\beta$-catenin signaling pathway through the miR-221-3p/ DKK2 axis (Table 1, Supplement Figure 1).

\section{NCRNA AND TAMOXIFEN RESISTANCE}

Tamoxifen is the most commonly used chemotherapeutic agent in the treatment of $\mathrm{BC}$, specifically the estrogen receptor (ER)positive BC subtype (32). Tamoxifen is considered a pioneering drug due to its ubiquitous use, cost-effectiveness, lifesaving properties, and being devoid of major side effects in the majority of BC patients (33). The ER-positive BC accounted for more than $70 \%$ of all breast cancers (34). However, ERpositive patients with metastatic disease poorly responded to tamoxifen therapy, and often with increased dose- and timedeveloped resistance to tamoxifen (35). For most ER-positive/ progesterone receptor (PR)-negative $\mathrm{BC}$ subtypes, the 5-year survival was still quite low ( 20\%) (36). The increased intrinsic and extrinsic factors are also responsible for the resistance toward chemotherapy in BC cells (37). It is quite urgent to better understand the mechanism of tamoxifen resistance and developed new therapies for BC.

\section{miRNAs in Tamoxifen Resistance}

Tamoxifen is often used for ER-positive BC treatment. However, the tumor cells could develop resistance to tamoxifen and limit its application. Gene regulation by miRNAs often leads to activation or dysregulation of various pathways responsible for the development of drug resistance (38). Different miRNAs have been reported to be potential indicators for drug sensitivity in BC cell lines (39). Many miRNAs associated with tamoxifen resistance have been identified and offer new targets for BC therapy (40). Gao et al. (41) reported that the decrease of miR$200 \mathrm{~b}$ and miR-200c reduced the expression of c-MYB and therefore elevated EMT marker vimentin and ZEB1/2 in tamoxifen-resistant ER-positive MCF-7 cells. Epiregulin (EREG), an EGFR agonist, plays a vital role in enhancing the process of glycolysis by activation of EGFR signaling and its downstream glycolytic genes in tamoxifen-resistant BC cells (42, 43). He et al. (44) found that in tamoxifen-resistant BC cells, EREG as a target of miR-186-3p and miR-186-3p is involved in $\mathrm{BC}$ cell resistance to tamoxifen. In HER2-positive tamoxifenresistant primary human breast tumors, miR-221 and miR-222 directly targeted p27Kip1 and are responsible for increasing cell apoptosis upon exposure with tamoxifen (45). Li et al. (46) reported that miR-449a performed its function by targeting ADAM22 and took part in the underlying mechanism of tamoxifen resistance in BC. Another research reported that overexpression of miR-451a promoted the sensitivity of tamoxifen in $\mathrm{BC}$ by regulating the macrophage migration inhibitory factor and $14-3-3 \zeta \operatorname{ER} \alpha(47,48)$. Ye et al. (49) examined the differential miRNA expression profiles between

TABLE 1 | Breast cancer anthracycline chemoresistance-related ncRNAs.

\begin{tabular}{|c|c|c|c|c|}
\hline ncRNA & Drugs & Function & Targets/mechanisms & References \\
\hline miR-200c & Doxorubicin & Sensitivity & Inhibition P-gp & Chen et al. (10) and Kopp et al. (11) \\
\hline miR-34a & Adriamycin & Sensitivity & Inhibition Notch1 & Li et al. (12) and Park et al. (13) \\
\hline $\mathrm{miR}-302 \mathrm{a} / \mathrm{b} / \mathrm{c} / \mathrm{d}$ & Adriamycin & Sensitivity & Activation P-gp MAPK/ERK & Zhao et al. (15) \\
\hline miR-148/152 & Adriamycin & Resistance & Inhibition SPIN1 & Chen et al. (16) \\
\hline miR-124-3p & Adriamycin & Sensitivity & Inhibition ABCC4 & Hu et al. (17) \\
\hline miR-298 & Adriamycin & Resistance & Inhibition P-gp & Bao et al. (18) \\
\hline miR-29a & Adriamycin & Resistance & Inhibition PTEN/AKT/GSK3 $\beta$ & Shen et al. (19) \\
\hline miR-130b & Adriamycin & Resistance & Inhibition PI3K/AKT & Miao et al. (20) \\
\hline miR-222 & Adriamycin & Resistance & Inhibition PTEN/AKT/p27 KIP1 & Wang et al. (21) \\
\hline $\mathrm{miR}-145$ & Doxorubicin & Sensitivity & Inhibition MRP1 & Gao et al. (22) \\
\hline miR-489 & Adriamycin & Sensitivity & Inhibition EMT/Smad3 & Jiang et al. (23) \\
\hline miR-760 & Doxorubicin & Resistance & Inhibition EMT/Nanog & Hu et al. (24) \\
\hline miR-192-5p & Doxorubicin & Sensitivity & Activation JNK/Bad/Caspase9, inhibition Bcl-2/PPIA & Zhang et al. (25) \\
\hline miR-221 & Adriamycin & Sensitivity & Inhibition hormone receptor(HR) & Zhao et al. (26) \\
\hline LncRNA-00518 & Adriamycin & Resistance & Inhibition miR-199a/MRP1 axis & Chang et al. (27) \\
\hline LncRNA-LINP1 & Doxorubicin & Resistance & Inhibition P53 & Liang et al. (28) \\
\hline LncRNA-NONHSAT101069 & Epirubicin & Resistance & Inhibition miR-129-5p/Twist1/EMT & Yao et al. (29) \\
\hline LncRNA-BORG & Doxorubicin & Resistance & Activation NF- $\mathrm{NB}$ signaling pathway & Gooding et al. (30) \\
\hline LncRNA-GAS5 & Adriamycin & Resistance & Inhibition Wnt/ $\beta$-Catenin & Chen et al. (31) \\
\hline
\end{tabular}


tamoxifen-resistant (MCF-7C and MCF-7T) and tamoxifensensitive (MCF-7) BC cell lines and showed that miR-21, miR27a, miR-146a, miR-148a, and miR-34a performed a major role in tamoxifen resistance in BC.

\section{LncRNAs in Tamoxifen Resistance}

Approximately $70 \%$ of BC patients have luminal A/ER-positive $(\mathrm{ER}+) \mathrm{BC}$ which consists of genes with low proliferation rates and low levels of HER2 (50). A previous study showed that several lncRNAs demonstrated important roles in tamoxifen resistance (51). Li et al. (52) revealed that long non-coding RNA UCA1 conferred tamoxifen resistance in BC endocrine therapy through activation of the EZH2/p21 axis and the PI3K/ AKT signaling pathway. Liu et al. (53) reported that lncRNA CYTOR has the function of promoting tamoxifen resistance in BC cells via sponging miR-125a-5p. Xue et al. (54) observed that LncRNA HOTAIR was upregulated in tamoxifen-resistant breast cancer tissues compared to their primary counterparts. Overexpression of HOTAIR increased the proliferation BC cells and enhanced their tamoxifen resistance. Ma et al. (55) determined that the expression of lncRNA LINP1 (nonhomologous end joining pathway 1) was increased in tamoxifen-resistant BC cells. Knockdown of lncRNA LINP1 significantly attenuated the tamoxifen resistance in vitro and in vivo. IncRNA HOTAIRM1 has been proved to be involved in myelopoiesis as well as transcription regulation of HOXA genes in embryonic stem cells. In BC cells, lncRNA HOTAIRM1 and HOXA1 are upregulated in tamoxifen-resistant MCF7 (TAMR) cells, and the knockdown of IncRNA HOTAIRM 1 downregulated the HOXA1 expression and restored the sensitivity to tamoxifen (56). Cyclin D1 is one of the most important cancer proteins that drive cancer cell proliferation and associate with tamoxifen resistance in BC. Shi et al. (57) proved that LncRNA DILA1 inhibits Cyclin D1 degradation and contributes to tamoxifen resistance in breast cancer. $\mathrm{Qu}$ et al. (58) reported that $\operatorname{lncRNA}$ BLACAT1 was significantly upregulated in tamoxifen-resistant $\mathrm{BC}$ cells $\mathrm{MCF}-7 / \mathrm{TR}$ and T47D/TR, and knockdown of IncRNA BLACAT1 reduced the tamoxifen resistance in the cells. Further study revealed that lncRNA BLACAT1 induced tamoxifen resistance through regulating the miR-503/Bcl-2 axis in BC. Ma et al. (59) reported that LncRNA DSCAM-AS1 enhanced BC cell tamoxifen resistance through acting as a sponge of miR-137. $\mathrm{Xu}$ et al. (60) found that tamoxifen-resistant BC cell-derived exosomes contain IncRNA urothelial cancer-associated 1 (UCA1), and the expression of IncRNA UCA1 increased tamoxifen resistance in BC. LncRNA UCA1 was also found to be involved in causing tamoxifen resistance in $\mathrm{BC}$ cell lines MCF7 and T47D by activating the $\mathrm{Wnt} / \beta$-Catenin signaling pathway (61) and mTOR signaling pathway (62). Shi et al. (63) identified that lncRNA ADAMTS9-AS2 has a lower expression in BC tissues and tamoxifen-resistant BC cells. A low expression of lncRNA ADAMTS9-AS2 inhibited PTEN expression and enhanced tamoxifen resistance through targeting miRNA130a-5p. Zhang et al. (64) revealed that downregulation of IncRNA ROR inhibited the BC cell EMT and enhanced the cell sensibility to tamoxifen through increasing miR-205 expression.

\section{CircRNAs in Tamoxifen Resistance}

CircRNAs are a group of ncRNAs which contributed to the gene regulation by competing the combination with endogenous RNA (ceRNA) mechanisms (65). CircRNAs often serve as transcription regulators, acting as microRNA sponges and expressing peptides under rare circumstances and sequestering RNA-binding proteins (RBPs) (66). Sang et al. (67) found that the expression of hsa_circ_0025202 enhanced tamoxifen efficacy and inhibited the progression of $\mathrm{BC}$ cells via regulating the miR182-5p/FOXO3a axis. Liang et al. (68) reported that knockdown of CircBMPR2 promoted tamoxifen resistance and inhibited apoptosis of BC cells via the circBMPR2/miR-553/USP4 axis. $\mathrm{Hu}$ et al. (69) showed that circ_UBE2D2 isolated from exosomes enhanced the resistance of $\mathrm{BC}$ cells to tamoxifen by binding to miR-200a-3p. Uhr et al. (70) revealed that miR-7 is connected with tamoxifen treatment outcomes in an adjuvant hormonenaïve cohort, and circRNA CDR1-AS regulated miR-7 function in BC. However, circRNA CDR1-AS has negative relevant outcomes in the cohort (Table 2, Supplement Figure 2).

\section{ncRNAs AND TAXANE RESISTANCE}

Taxanes are an important class of antineoplastic agents often used for treatment of a wide variety of cancers. Paclitaxel and docetaxel are the most commonly used taxanes, which elicit immediate hypersensitivity reactions (HSRs) in 5\% to $10 \%$ of patients (71). Almost all patients that experience HSRs can be safely reexposed to taxanes. Taxanes not only strengthen BC treatment but also are capable of developing resistance following mortality and metastatic disease (72). Taxanes are cytotoxic because they inhibit the depolymerization of tubulin microtubules and affect the process of mitosis in the $\mathrm{M}$ or G1 phase. Furthermore, it is also reported that the antineoplastic activity of taxanes is significantly involved in certain biological processes including angiogenesis, apoptosis, cell motility, invasiveness, and metalloproteinase production (73). Triplenegative breast cancer (TNBC) is a heterogeneous disease with various prognoses and chemosensitivity profiles, and the standard therapy includes the mainstay treatment with anthracyclines and taxanes (74). Although there have been many studies for exploring the cause of taxane resistance in $\mathrm{BC}$, the mechanism of the process is still unknown. ncRNAs could regulate the expression of drug resistance gene and thereby influence the $\mathrm{BC}$ cell progression and development of chemotherapy resistance (75).

\section{ncRNAs in Paclitaxel Resistance miRNAs in Paclitaxel Resistance}

Various miRNAs have been reported to be related to different cancers (76). In BC cells, Lin28/let-7 is related to paclitaxel resistance and the Lin 28 miRNA level is intensely improved in tissues of tumors following neoadjuvant chemotherapy (77). Lin 28 has conferred specified cancer stem cells to BC cells and help the cells to gain the properties of "stemness" so that they can escape from the effect of chemotherapy. Overexpression of Lin28 
TABLE 2 | Breast cancer tamoxifen chemoresistance-related ncRNAs.

\begin{tabular}{|c|c|c|c|c|}
\hline ncRNA & Drugs & Function & Targets/mechanisms & References \\
\hline $\mathrm{miR}-200 \mathrm{~b} / \mathrm{c}$ & Tamoxifen & Sensitivity & Activation of vimentin/ZEB/EMT & Gao et al. (41) \\
\hline miR-186-3p & Tamoxifen & Resistance & Activation of EREG/EGFR & He et al. (44) \\
\hline miR-221/222 & Tamoxifen & Resistance & Inhibition of p27 Kip1 & Miller et al. (45) \\
\hline miR-449a & Tamoxifen & Sensitivity & Inhibition of ADAM22 & Li et al. (46) \\
\hline$m i R-451 a$ & Tamoxifen & Sensitivity & Inhibition of MIF & Liu and Liu et al. $(47,48)$ \\
\hline IncRNA-UCA1 & Tamoxifen & Resistance & Activation of PI3K/AKT & Li et al. (52) \\
\hline IncRNA-CYTOR & Tamoxifen & Resistance & Activation of SRF and Hippo signaling pathway & Liu et al. (53) \\
\hline IncRNA-HOTAIR & Tamoxifen & Resistance & Activation of ER signaling & Xue et al. (54) \\
\hline IncRNA-LINP1 & Tamoxifen & Sensitivity & Inhibition of ER and EMT & Ma et al. (55) \\
\hline IncRNA-HOTAIRM1 & Tamoxifen & Resistance & Inhibition of HOXA1 & Kim et al. (56) \\
\hline IncRNA-DILA1 & Tamoxifen & Sensitivity & Inhibition of Cyclin D1 & Shi et al. (57) \\
\hline IncRNA-BLACAT1 & Tamoxifen & Resistance & Activation of miR-503/Bcl-2 axis & Qu et al. (58) \\
\hline IncRNA-DSCAM-AS1 & Tamoxifen & Resistance & Activation of EPS8 & Ma et al. (59) \\
\hline IncRNA-UCA1 & Tamoxifen & Resistance & & Xu et al. (60) \\
\hline IncRNA-UCA1 & Tamoxifen & Resistance & Activation of Wnt/beta-Catenin signaling pathway & Liu et al. (61) \\
\hline IncRNA-UCA1 & Tamoxifen & Resistance & Inhibition of mTOR signaling pathway & Wu et al. (62) \\
\hline IncRNA-ADAMTS9-AS2 & Tamoxifen & Sensitivity & Inhibition of PTEN & Shi et al. (63) \\
\hline IncRNA-ROR & Tamoxifen & Resistance & Inhibition of EMT & Zhang et al. (64) \\
\hline circRNA-0025202 & Tamoxifen & Sensitivity & Inhibition of FOXAЗа & Sang et al. (67) \\
\hline circRNA-BMPR2 & Tamoxifen & Sensitivity & Inhibition of the miR-553/USP4 axis & Liang et al. (68) \\
\hline circRNA-UBE2D2 & Tamoxifen & Resistance & Inhibited of miR-200a-3p & Hu et al. (69) \\
\hline circRNA-CDR1-AS & Tamoxifen & Resistance & Inhibition of hsa-miR-7 & Uhr et al. (70) \\
\hline
\end{tabular}

is capable of inducing $\mathrm{Rb}$ and $\mathrm{p} 21$ expression and decreasing the level of let-7a (78). Tsang also reported that let-7a directly targeted caspase 3 and promoted the resistance in paclitaxelinduced apoptosis (79). Tao et al. (80) proved that downregulation of let- $7 \mathrm{f}$ was associated with its target thrombospondin-1 (TSP-1) and thus influenced the cell sensibility to paclitaxel in MCF-7 cells. With the help of the miRNA array, Zhou et al. (81) observed the upregulation of miR125b, miR-221, miR-222, and miR-923 in paclitaxel-resistant BC cells. They also proved that miR-125b can inhibit the paclitaxelinduced apoptosis and cytotoxicity by suppressing the expression of pro-apoptotic Bcl2 antagonist killer 1 (BAK1) in BC cells.

Another miRNA involved in paclitaxel resistance was miR$520 \mathrm{~h}$; the increased expression of miR-520h was correlated with negligible prognosis and lymph node metastasis in human BC patients. The expression of miR-520h promoted paclitaxel resistance of human breast cancer cells through suppressing death-associated protein kinase 2 (DAPK2) expression and protecting the cells from paclitaxel-induced apoptosis (82). Gu et al. (83) reported that miR-451 possesses a significant influence to the sensibility of neoadjuvant chemotherapy by inhibiting the expression of Bcl-2 and the process of apoptosis induced by paclitaxel. The luminal A subtype was a special type of $B C$ which exhibited $\mathrm{ER}^{+} / \mathrm{PR}^{+}$and HER2 (84). In luminal A BC cells, miR100 proved to sensitize the cells to paclitaxel treatment in part by targeting the mTOR signaling pathway. The results showed that microRNA 100 plays important roles for luminal A subtype BC cell resistance to paclitaxel (85). In TNBC cells, overexpression of miR-18a was reported to reduce the expression of DICER and enhance autophagy and paclitaxel resistance by inhibiting the mTOR signaling pathway (86). Liu et al. (87) illustrated that the expression of miR-101 in TNBC cells significantly inhibited the effects of tumorigenesis in vivo and growth and apoptosis in vitro. Besides, miR-101 also increased paclitaxel sensitivity by suppressing myeloid cell leukemia-1 (MCL-1) expression in TNBC cells.

\section{LncRNAs in Paclitaxel Resistance}

Arun et al. (88) reviewed the function and mechanism of lncMALAT1 (MALAT1) in BC and proved that the patients with elevated MALAT1 showed worse prognosis. Yu et al. (89) used MCF-7/Tax (taxane-resistant MCF-7 cells) and MCF-7/Adr (adriamycin-resistant MCF-7 cells) cells as research objects. They found that MALAT1 exhibited a significantly high level in the cells, and knockdown of MALAT1 decreased the sensitivity of the cells to taxane and adriamycin. Zheng et al. (90) found that long non-coding RNA CASC2 (CASC2) regulated the expression of miR-18a-5p/CDK19 and activated paclitaxel resistance in $\mathrm{BC}$. Thus, they highlighted the significance of the CASC2/miR-18a-5p/CDK19 axis in the chemoresistance of $\mathrm{BC}$ and provided potential aims to improve the chemotherapy of $\mathrm{BC}$.

Unlike $\mathrm{ER}^{+}$and $\mathrm{HER}^{+} \mathrm{BC}$, TNBC patients are primarily treated with chemotherapy. Paclitaxel is the first-line taxanebased chemotherapeutic agent that is used for the treatment of TNBC patients (91). Si et al. showed that IncRNA H19 was one of the downstream target molecules of ER $\alpha$. Altered ER $\alpha$ expression could change H19 levels and modulate the apoptosis response to chemotherapy in $\mathrm{BC}$ cells. They also suggested that the ER $\alpha-\mathrm{H} 19-\mathrm{BIK}$ signaling axis plays an important role in promoting chemoresistance for Er $\alpha+\mathrm{BC}$ to paclitaxel (92). Raveh et al. (93) found that lncRNA-H19 was elevated in TNBC paclitaxel-resistant cell lines compared to parental cells. LncRNA-H19 was highly expressed during embryonic development but decreased after birth, specifically in mammary tissue. Knockdown of lncRNA-H19 in paclitaxelresistant TNBC cell lines increased paclitaxel sensitivity by reducing p-AKT (Ser473) and decreasing the apoptotic rate 
(94). Chen et al. (95) identified that Linc00839 was localized in the nucleus and upregulated in chemoresistant $\mathrm{BC}$ cells and tissues. The expression of Linc00839 was activated by Myc and promoted proliferation and chemoresistance in breast cancer through binding with Lin28B via activation of the PI3K/AKT signaling pathway.

\section{CircRNA in Paclitaxel Resistance}

circRNAs also play vital roles in the paclitaxel resistance of BC cells. $\mathrm{Ma}$ et al. (96) identified that circular RNA angiomotin-like 1 (circAMOTL1) has high correlations with paclitaxel resistance in BC cells. circAMOTL1 regulated the AKT pathway and facilitated the anti-apoptotic protein expression which led to paclitaxel resistance in BC cells. Yang et al. (97) reported that circ-ABCB10 bound with let-7a-5p and promoted paclitaxel sensitivity and apoptosis while suppressing invasion and autophagy of paclitaxelresistant BC cells. Zang et al. (98) proved that circ-RNF111 was upregulated in paclitaxel-resistant BC tissues and cells. Knockdown of circ-RNF111 reduced the function of paclitaxel on BC cells. They further identified miR-140-5p as a target of circ-RNF111, and circRNF111 improved paclitaxel resistance of BC cells by upregulating E2F3 via sponging miR-140-5p (Table 3, Supplement Figure 3).

\section{ncRNAs in Docetaxel Resistance miRNAs in Docetaxel Resistance}

Docetaxel (a semi-synthetic paclitaxel analog) was synthesized by the precursor obtained from the needles of the European yew. Paclitaxel and docetaxel both performed their function by inhibiting mitotic activity and suppressed the polymerization of microtubules (99). There are various miRNAs whose downregulation plays a vital role in BC cell docetaxel resistance $(100,101)$. For example, an in vitro study revealed that the elevated level of miR-129-3p was interlinked with docetaxel resistance by directly inhibiting the apoptosisassociated protein eukaryotic translation initiation factor $4 \mathrm{E}$ (EIF4E). Downregulation of miR-141 resulted in a decrease of EIF4E/CP110 and provided an apoptosis-inducing effect (102). Another study revealed that miR-129-3p promoted docetaxel resistance of $\mathrm{BC}$ cells via inhibiting the expression of centriolar coiled-coil protein 110 (CP110) (103). In MCF-7 and MDA-MB$231 \mathrm{BC}$ cell lines, an upregulation of miR-3646 was related to docetaxel resistance through activating the GSK-3 $\beta / \beta$-catenin signaling pathway (104). Hu et al. (105) observed the expression of miR-663, and miR-452 was increased in docetaxel-resistant BC cell lines MDAMB-231 and MCF-7. MiR-452 contributed to the docetaxel resistance by inhibiting anaphase-promoting complex subunit 4 (APC4) expression, while overexpression of miR-663 caused the downregulation of heparin sulfate proteoglycan 2 (HSPG2) and induced BC cell chemoresistance (106). In extensive research, Kaslt et al. (107) conducted a microarray analysis of MDA-MB-231 and MCF-7 cell lines between docetaxel resistance and miRNA expression. The results showed that miR-141 and miR-34a were increased and miR-16, miR-7, miR-30a, miR-126, and miR-125a-5p were decreased in docetaxel resistance cells. Zhang et al. (108) also analyzed miRNA array and found that miR-139-5p was significantly downregulated in $\mathrm{BC}$ cells compared to vicinal typical tissue. The in vitro research revealed that miR-139-5p was capable of inhibiting $\mathrm{BC}$ cell growth and induced apoptosis by targeting Notch 1 and hence decreasing the docetaxel resistance. Besides, miR-205 was reported to increase the sensitivity of MDA-231 and MCF-7 cells against docetaxel via inhibition of clonogenic capability and cell proliferation (109).

$\mathrm{Xu}$ et al. (110) found that miR-125a was downregulated in docetaxel-resistant BC cells, and overexpression of miR-125a enhanced the cells' docetaxel sensitivity by suppressing the BRCA1 expression. The authors also observed that the level of miR-125a was decreased in the HER-2 and metastatic specimens of BC patients. The outcome provided a novel approach toward increased sensitivity of BC patients against docetaxel via overexpression of miR125a. Generally, a combined therapy of docetaxel plus adriamycin is used to treat metastatic and reoccurrence $\mathrm{BC}$ patients. However, development of drug resistance remains a latent problem, and miR-222 and miR29a have been reported to increase in docetaxel plus adriamycinresistant BC cell lines. Further research proved that the two miRNAs are potential inhibitors that altered the drug resistance and restored their sensitivity by targeting PTEN and activating the Akt/mTOR approach (111).

Exosomes, a group of 40-100-nm-nanosized vesicles that lived in the extracellular space of cells, perform as genome exchange vehicles between heterogeneous tumor cells. Exosomes are also

TABLE 3 | Breast cancer paclitaxel chemoresistance-related ncRNAs.

\begin{tabular}{|c|c|c|c|c|}
\hline ncRNA & Drugs & Function & Targets/mechanisms & References \\
\hline Lin28 & Paclitaxel & Resistance & Activation of p21 and Rb; inhibition of Let-7 & Lv et al. (78) \\
\hline Let-7a & Paclitaxel & Resistance & Inhibition of caspase-3 & Tsang et al. (79) \\
\hline mi-125b & Paclitaxel & Resistance & Inhibition of BAK1 & Zhou et al. (81) \\
\hline mi-520h & Paclitaxel & Resistance & Inhibition of DAPK2 & Su et al. (82) \\
\hline mi-451 & Paclitaxel & Resistance & Inhibition of Bcl-2 & Gu et al. (83) \\
\hline mi-100 & Paclitaxel & Sensitivity & Inhibition of the Mtor signaling pathway & Zhang et al. (85) \\
\hline mi-18a & Paclitaxel & Resistance & Inhibition of the mTOR signaling pathway & Sha et al. (86) \\
\hline mi-101 & Paclitaxel & Sensitivity & Inhibition of MCL-1 & Liu et al. (87) \\
\hline LncRNA-CASC2 & Paclitaxel & Resistance & Inhibition miR-18a-5p/CDK19 & Zheng et al. (90) \\
\hline LncRNA-H19 & Paclitaxel & Resistance & Inhibition AKT/BIK & Si et al. (92) and Raveh et al. (93) and Han et al. (94) \\
\hline LncRNA-00839 & Paclitaxel & Resistance & Activation PI3K/AKT signaling pathway & Chen et al. (95) \\
\hline CircRNA-ABCB10 & Paclitaxel & Resistance & Inhibition of the let-7a-5p/DUSP7 axis & Yang et al. (97) \\
\hline CircRNA-RNF111 & Paclitaxel & Resistance & Inhibition of miR-140-5p/E2F3 & Zang et al. (98) \\
\hline
\end{tabular}


capable of transferring drug resistance to desired cells through the miRNAs they contained. Chen et al. (112) reported that miR-23a, miR-1246, miR-1469, let-7b, miR-38 and miR-1915 were found in docetaxel-resistant cell exosomes, illustrating that these exosomes play important roles in the drug resistance cells.

\section{LncRNAs in Docetaxel Resistance}

Huang et al. (113) performed RNA sequencing and analyzed that mRNAs and lncRNAs contribute to docetaxel resistance in two docetaxel-resistant BC cell lines MCF7-RES and MDA-RES and their docetaxel-sensitive parental cell lines. Co-expression network and location analysis revealed that four lncRNAs might upregulate the expression of ABCB1 and influence the cells' drug resistance. The author also identified the lncRNA EPB41L4A-AS2 (EPB41L4A antisense RNA 2) as a potential biomarker for docetaxel sensitivity BC cells. Shin et al. (114) revealed that the combination of cisplatin or taxol and NEAT1 (lncRNA nuclear paraspeckle assembly transcript 1) knockdown synergistically inhibited the cells' sensitivity to the drug when compared with cisplatin or taxol alone. Overexpression of NEAT1 in cisplatinand taxol-resistant TNBC cells indicated its function of chemoresistance in BC cells (Table 4, Supplement Figure 4).

\section{ncRNAs IN 5-FLUOROURACIL RESISTANCE}

5-Fluorouracil (5-FU) is a classic chemotherapeutic drug, and it has been extensively used to treat different cancers (115). However, patients often exhibited primary or acquired drug resistance during treatments. Although there are many advancements in bioresearch technologies in the past several decades, the molecular mechanisms of 5-FU resistance have not been completely clarified (116). ncRNAs as oncogenes or tumor suppressors often play a vital role in BC cells and contributed to 5-FU drug resistance (117).

\section{miRNAs in 5-FU Resistance}

Nandy et al. (118) proved that microRNA-125a influences breast cancer stem cells by posttranscriptionally regulating the leukemia inhibitory factor (LIF) receptor gene expression via binding with its 3 '-untranslated region (UTR), thus regulating the cells' drug resistance to 5-FU through the Hippo signaling pathway. Zhang et al. (119) reported that the interaction between miR-508-5p and Pgp or ZNRD1 was responsible for 5-FU chemotherapeutic resistance. Moreover, Yin et al. (120) indicated that the direct repression of Bmil expression under the action of miR-200c and miR-203 could alter the Bmil-mediated 5-FU resistance. Li et al. (121) illustrated that chemotherapeutics like 5-FU was involved in the suppression of miR-488 and which in turn activated the epidermal growth factor receptor (EGFR)/nuclear factor kappaB $(\mathrm{NF}-\mathrm{\kappa B})$ signaling approach via targeting SATB1.

\section{LncRNAs in 5-FU Resistance}

Several studies have been conducted to analyze the 5-FU resistance-related upregulation and downregulation of lncRNAs in BC. Redis et al. (122) reported that upregulation of Lnc-CCAT2 correlated with the sensitivity to 5-FU in BC cells. The ncRNA nuclear paraspeckle assembly transcript 1 (NEAT1) present at an elevated level in BC cells, especially in stage III-IV tumors vs. overexpression of lncRNA NEAT1, was related to the poor prognosis and metastasis of BC. Li et al. (123) conducted in vitro assays to understand the biological function of Lnc NEAT1 and observed that NEAT1 was involved in the sponging of miR211 and induced BC cell resistance to 5-FU. The group of Chen and Hou reported that overexpression of LncROR was connected with BC cell EMT and therefore improved the cells' invasion capability and resistance to 5-FU. This result suggests that upregulation of LncROR can be considered to be a potential drug resistance marker $(124,125)$. A recent research by Yao et al. (126) found that the ER stress induced by 5-FU could increase the expression of GRP78 in MCF-7 cells. GRP78 then regulated the expression of LncMIAT and AKT through upregulating Oct4, thereby increasing the $\mathrm{BC}$ cells' resistance to 5-FU. The conclusion was that LncMIAT participated in $\mathrm{BC}$ cell resistance to 5-FU through the ER stress-mediated GRP78/Oct4/lncRNA MIAT/AKT pathway. Luo et al. (127) reported that overexpression of lncRNA SNORD3A specifically sensitizes breast cancer cells to 5-FU via enhancing UMPS expression. The SNORD3A-UMPS axis may serve as a potential biomarker and therapeutic target to improve the efficacy of 5-FU-based chemotherapy for BC patients.

\section{CircRNA in 5-FU Resistance}

circRNAs are a class of ncRNA which have a circle structure. circRNAs have been discovered in various cancers and acted as

TABLE 4 | Breast cancer docetaxel chemoresistance-related ncRNAs.

\begin{tabular}{|c|c|c|c|c|}
\hline ncRNA & Drugs & Function & Targets/mechanisms & References \\
\hline $\operatorname{miR}-141$ & Docetaxel & Sensitivity & Activation of EIF4E/CP110 & Yao et al. (102) \\
\hline miR-129-3p & Docetaxel & Resistance & Inhibition of CP110 & Zhang et al. (103) \\
\hline miR-3646 & Docetaxel & Resistance & 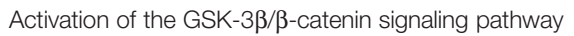 & Zhang et al. (104) \\
\hline miR-452 & Docetaxel & Resistance & Inhibition of APC4 & Hu et al. (105) \\
\hline miR-663 & Docetaxel & Resistance & Inhibition of HSPG2 & Hu et al. (106) \\
\hline miR-139-5p & Docetaxel & Resistance & Inhibition of Notch1 & Zhang et al. (108) \\
\hline $\operatorname{miR}-125 a-3 p$ & Docetaxel & Sensitivity & Inhibition of BRCA1 & Xu et al. (110) \\
\hline miR-222/29a & Docetaxel & Resistance & Activation of Akt/mTOR & Zhong et al. (111) \\
\hline LncRNA-EPB41L4A-AS2 & Docetaxel & Sensitivity & Activation of $\mathrm{ABCB} 1$ & Huang et al. (113) \\
\hline LncRNA-NEAT1 & Docetaxel & Resistance & Activation of Sox2/ALDH & Shin et al. (114) \\
\hline
\end{tabular}


either promoting tumorigenesis or inhibiting tumor progression (128). Regarding research on circRNAs and BC cell chemoresistance, only Yang et al. reported about circRNA CDRlas, implicating its function in regulating 5-FU sensitivity in BC cells (129). In the study, they found that circRNA CDR1as competitively inhibited miR-7 to regulate CCNE1 expression. The overexpression of circRNA CDRlas reversed the enhancement of 5-FU sensitivity in BC cells caused by overexpression of miR-7. The study proved that circRNA CDRlas regulated the sensitivity of 5-FU-resistant BC cells by inhibiting miR-7 to regulate CCNE1 (Table 5, Supplement Figure 5).

\section{NCRNAS IN TRASTUZUMAB RESISTANCE}

The human epidermal growth factor receptor 2 (HER-2) is often used to classify the BC patients with overexpression (known as HER-2 positive) or not (HER-2 negative) (130). There is a high correlation between HER-2 upregulation and BC metastasis as well as poor prognosis (131). Trastuzumab (TRS), a HER-2targeting humanized monoclonal antibody, is a selective treatment that targets HER-2 (132). ncRNA provides a comprehensive understanding of their mechanism of action and function and crucial contribution in regulating BC drug resistance and metastasis (133).

\section{miRNAs in Trastuzumab Resistance}

To validate the mechanism of miRNAs in BC trastuzumab resistance, several studies were conducted in vivo and in vitro. Gong and De Mattos et al. $(134,135)$ found that upregulation of miR-21 significantly correlated with $B C$ resistance to trastuzumab by activation of PTEN, inhibition of AKT, and sustenance of EMT. However, Nielsen et al. (136) reported that the expression of miR-21 in primary breast cancer may not predict its resistance to adjuvant trastuzumab treatment. Ye et al. (137) proved that miR-221 promoted HER-2-positive BC against trastuzumab through suppressing PTEN expression. Besides, the circulating level of miR-210 in plasma was found to be correlated with HER-2-positive BC patients who are trastuzumab resistant, indicating that plasma miR-210 could serve as a predictive biomarker in surveillance of the therapeutic responsiveness (138). Bai et al. (139) found that miR-200c counteracts trastuzumab resistance and metastasis by inhibiting ZNF217 and ZEB1 and TGF-beta signaling pathway expression in BC. Ye and Ma et al. $(140,141)$ reported that downregulation of miR5423p and miR-375 contributed to induction of TRS resistance in HER-2-positive breast cancer through inhibition of IGF1R and activation of the PI3K/AKT signaling pathway. Corcoran et al. (142) proved that downregulation of miR-630 tightly connected with HER-2-targeting drugs in HER-2overexpressing $\mathrm{BC}$ by inhibition of IGF1R. Venturutti et al. (143) found that mir-16 was upregulated in HER-2-positive breast cancer and mir-16 mediated trastuzumab and lapatinib response in ErbB-2-positive breast cancer via its novel targets CCNJ and FUBP1. Huynh et al. (144) reported that microRNA-7 reversed TRS resistance by HER-2 Delta16 and multiple oncogenic pathways in breast cancer cells.

\section{LncRNAs in Trastuzumab Resistance}

LncRNA, as a group of ncRNA, also played an important role in $\mathrm{HER}^{+} \mathrm{BC}$ trastuzumab resistance, but its contribution to $\mathrm{BC}$ resistance is still unclear. Trastuzumab was considered to be the first-line therapy drug to treat advanced HER2 ${ }^{+}$BC (145). It was reported that LncRNA-SNHG14 was responsible for mediating trastuzumab via extracellular exosomes of tumor cells. Exosomal lncRNA-SNHG14 activated the Bcl-2/Bax apoptosis signaling pathway and induced resistance against trastuzumab in BC cells. When treating the cells with trastuzumab-resistant cell-derived exosomes, the cell apoptosis and death were remarkably decreased (146). Dong et al. (147) reported that lncRNA AGAP2-AS1 promoted the growth of BC and trastuzumab resistance by upregulation of MyD88 expression by activating the NF- $\kappa \mathrm{B}$ signaling approach. Based on the microarray analysis, Shi et al. (148) observed that lncRNA-ATB was elevated in five trastuzumab-resistant $\mathrm{BC}$ patients. Further study revealed that lncRNA-ATB promoted trastuzumab resistance via activating the EMT and TGF- $\beta$ signaling pathway in BC cells. Li et al. (149) reported the significant downregulation of LncGAS5-activated miR21 and mTOR signaling pathway in trastuzumab-resistant SKBR-3 cells and trastuzumab-resistant BC patients. Han et al. (150) observed that lncZNF649-AS1 was highly expressed in trastuzumab-resistant cells compared to sensitive cells. lncZNF649-AS1 was upregulated by H3K27ac modification in the presence of trastuzumab treatment. Knockdown of ZNF649AS1 reversed trastuzumab resistance via modulating ATG5

TABLE 5 | Breast cancer fluorouracil chemoresistance related ncRNAs.

\begin{tabular}{|c|c|c|c|c|}
\hline ncRNA & Drugs & Function & Targets/mechanisms & References \\
\hline miR-125a & Fluorouracil & Resistance & Inhibition LIF/Hippo signaling pathway & Nandy et al. (118) \\
\hline miR-508-5p & Fluorouracil & Resistance & Inhibition P-gp or ZNRD1 & Zhang et al. (119) \\
\hline miR-200/203 & Fluorouracil & Sensitivity & Inhibition P53/Bmi1 & Yin et al. (120) \\
\hline $\mathrm{miR}-448$ & Fluorouracil & Resistance & Inhibition EMT/NFkB & Li et al. (121) \\
\hline LncRNA-NEAT1 & Fluorouracil & Resistance & Inhibition miR-211/HMGA2 & Li et al. (123) \\
\hline LncRNA-RoR & Fluorouracil & Resistance & Activation EMT & Chen et al. (124) \\
\hline LncRNA-ROR & Fluorouracil & Resistance & & Hou et al. (125) \\
\hline LncRNA-MIAT & Fluorouracil & Resistance & Activation GRP78/OCT4/AKT pathway & Yao et al. (126) \\
\hline LncRNA-SNORD3A & Fluorouracil & Sensitivity & Activation UMPS & Luo et al. (127) \\
\hline Circ-CDR1as & Fluorouracil & Resistance & Inhibition miR-7/CCNE1 & Yang et al. (129) \\
\hline
\end{tabular}


TABLE 6 | Breast cancer trastuzumab chemoresistance-related ncRNAs.

\begin{tabular}{|c|c|c|c|c|}
\hline ncRNA & Drugs & Function & Targets/mechanisms & References \\
\hline miR-21 & Trastuzumab & Resistance & 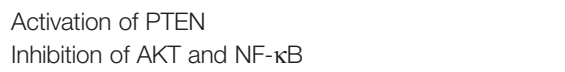 & Gong and De Mattos et al. $(134,135)$ \\
\hline miR-221 & Trastuzumab & Resistance & Inhibition of PTEN & Ye et al. (137) \\
\hline $\mathrm{miR}-200 \mathrm{c}$ & Trastuzumab & Resistance & Inhibition of ZNF217/ZEB1/TGF- $\beta$ signaling pathway & Bai et al. (139) \\
\hline miR-375 & Trastuzumab & Sensitivity & Inhibition of IGF1R, & Ye et al. (140) \\
\hline miR-542-3p & Trastuzumab & Sensitivity & Activation of PIउK/AKT & Ma et al. (141) \\
\hline miR-630 & Trastuzumab & Sensitivity & Inhibition of IGF1R & Corcoran et al. (142) \\
\hline $\operatorname{miR}-16$ & Trastuzumab & Sensitivity & Inhibition of CCNJ and FUBP1 & Venturutti et al. (143) \\
\hline miR-7 & Trastuzumab & Resistance & Inhibition of EGFR & Huynh et al. (144) \\
\hline LncRNA-SNHG14 & Trastuzumab & Sensitivity & Activation of Bcl-2/Bax & Dong et al. (146) \\
\hline LncRNA-AGAP2-AS1 & Trastuzumab & Resistance & Activation of MyD88/NF- $\mathrm{BB}$ signaling pathway & Dong et al. (147) \\
\hline LncRNA-ATB & Trastuzumab & Resistance & Activation of EMT/TGF- $\beta$ signaling & Shi et al. (148) \\
\hline LncRNA-GAS5 & Trastuzumab & Sensitivity & Activation of miR21/mTOR signaling pathway & Li et al. (149) \\
\hline LncRNA-ZNF649-AS1 & Trastuzumab & Resistance & Activation of ATG5/PTBP1 & Han et al. (150) \\
\hline LncRNA-HOTAIR & Trastuzumab & Resistance & Activation of TGF- $\beta$ signaling pathway & Chen et al. (151) \\
\hline
\end{tabular}

expression. Chen et al (151) found that LncRNA HOTAIR was highly expressed in trastuzumab-resistant cell line SK-BR-3-TR, and blocking of HOTAIR expression restores the sensitivity. LncRNA HOTAIR is involved in BC cell trastuzumab resistance via epigenetic modification of methylation in PTEN and therefore activation of the TGF- $\beta$ signaling pathway (Table $\mathbf{6}$, Supplement Figure 6).

\section{CONCLUSION}

Drug resistance is one of the main causes of BC therapy failure in clinical settings. It is also a complex process involving multiple factors, multiple steps, and multiple genes. Despite a number of novel agents that have been developed, the truly efficient options with minimal adverse effects for BC treatment remain limited. In this article, we summarized the mechanisms of ncRNAs in BC drug resistance, including chemotherapeutic, endocrine, and targeted drug resistance. Based on the reports, the molecular mechanisms of ncRNAs involved in BC drug resistance include 1) ncRNAs as a target gene of drugs and influencing its effects, 2) ncRNAs acting as ceRNAs to modulate BC cell sensitivity and drug resistance, 3) ncRNAs regulating cancer cell apoptosis and cell cycle transfer, and 4) ncRNAs inducing BC cell drug resistance through $\mathrm{NF}-\mathrm{KB}, \mathrm{mTOR}$, and $\mathrm{Wnt} / \beta$-catenin signaling pathways.

Even though there are many studies about the mechanism of ncRNAs in BC drug resistance, some of them even highlighted ncRNAs as a novel target for achieving improved treatment outcomes for BC patients. The mechanism of ncRNA networks regulating drug resistance and the selection of key targets from numerous candidate ncRNAs remain challenging. Besides, despite that most of current studies used human BC cell lines cultured in vitro, there still lack clinical studies to explore the mechanism of ncRNAs in BC drug resistance.

Although we reviewed the most research of ncRNA in BC drug resistance in this article, the details of mechanism still need further exploring. With the development of technology and the new research elucidates, we believe that targeting ncRNAs could be a novel strategy for achieving improved treatment outcomes for $\mathrm{BC}$ patients in the future.

\section{AUTHOR CONTRIBUTIONS}

L-bW contributed to the conception and design of this study. The acquisition of data was carried out by S-hL and C-yY. The analysis of data was carried by J-hT. All authors contributed to the article and approved the submitted version.

\section{FUNDING}

This study was funded by the Science and Technology Projects of Ningxia Key R\&D Programs (No. 2019BFH02012, 2021BEG03089); The National Natural Science Foundation of China (No. 81860470); The Ningxia High Level Science and Technology Innovation Leading Talent Project (No. KJT2019003); The Ningxia Biochip Technology Research and Development Innovation Team (No. 2019-18); The Scientific Research Platform Open Project of the General Hospital of Ningxia Medical University (No. 2020-146); The Science Research Project of Ningxia Medical University (No.XM2018099); The Science Research Project of the General Hospital of Ningxia Medical University (No. XM2020159). The First-Class Discipline Construction Project of NingXia Medical University and the School of Clinical Medicine (No. NXYLXK2017A05).

\section{SUPPLEMENTARY MATERIAL}

The Supplementary Material for this article can be found online at: https://www.frontiersin.org/articles/10.3389/fonc.2021. 702082/full\#supplementary-material

Supplementary Figure 1 | The pattern diagram of ncRNAs and Anthracyclines chemoresistance.

Supplementary Figure 2 | The pattern diagram of ncRNAs and Tamoxifen chemoresistance. 
Supplementary Figure 3 | The pattern diagram of ncRNAs and Paclitaxel chemoresistance.

Supplementary Figure 4 | The pattern diagram of ncRNAs and Docetaxel chemoresistance.

\section{REFERENCES}

1. Sung H, Ferlay J, Siegel RL, Laversanne M, Soerjomataram I, Jemal A, et al. Global Cancer Statistics 2020: GLOBOCAN Estimates of Incidence and Mortality Worldwide for 36 Cancers in 185 Countries. CA Cancer J Clin (2021) 71(3):209-49. doi: 10.3322/caac.21660

2. Koual M, Tomkiewicz C, Cano-Sancho G, Antignac JP, Bats AS, Coumoul X. Environmental Chemicals, Breast Cancer Progression and Drug Resistance. Environ Health (2020) 19(1):117-42. doi: 10.1186/s12940-020-00670-2

3. Slack FJ, Chinnaiyan AM. The Role of Non-Coding RNAs in Oncology. Cell (2019) 179(5):1033-55. doi: 10.1016/j.cell.2019.10.017

4. Mendell JT. Targeting a Long Noncoding RNA in Breast Cancer. N Engl J Med (2016) 374:2287-9. doi: 10.1056/NEJMcibr1603785

5. Yao RW, Wang Y, Chen LL. Cellular Functions of Long Noncoding RNAs. Nat Cell Biol (2019) 21:542-51. doi: 10.1038/s41556-019-0311-8

6. Uchida S, Adams JC. Physiological Roles of non-Coding RNAs. Am J Physiol Cell Physiol (2019) 317(1):C1-2. doi: 10.1152/ajpcell.00114.2019

7. Chen F, Chen J, Yang L, Liu J, Zhang X, Zhang Y, et al. Extracellular VesiclePackaged HIF-1alpha-Stabilizing lncRNA From Tumour-Associated Macrophages Regulates Aerobic Glycolysis of Breast Cancer Cells. Nat Cell Biol (2019) 21:498-510. doi: 10.1038/s41556-019-0299-0

8. Shah AN, Gradishar WJ. Adjuvant Anthracyclines in Breast Cancer: What Is Their Role? Oncologist (2018) 23:1153-61. doi: 10.1634/theoncologist.2017-0672

9. Bhagat A, Kleinerman ES. Anthracycline-Induced Cardiotoxicity: Causes, Mechanisms, and Prevention. Adv Exp Med Biol (2020) 1257:181-92. doi: 10.1007/978-3-030-43032-0_15

10. Chen J, Tian W, Cai H, He H, Deng Y. Down-Regulation of microRNA-200c is Associated With Drug Resistance in Human Breast Cancer. Med Oncol (2012) 29:2527-34. doi: 10.1007/s12032-011-0117-4

11. Kopp F, Oak PS, Wagner E, Roidl A. miR-200c Sensitizes Breast Cancer Cells to Doxorubicin Treatment by Decreasing TrkB and Bmil Expression. PloS One (2012) 7:e50469. doi: 10.1371/journal.pone.0050469

12. Li XJ, Ji MH, Zhong SL, Zha QB, Xu JJ, Zhao JH, et al. MicroRNA-34a Modulates Chemosensitivity of Breast Cancer Cells to Adriamycin by Targeting Notch1. Arch Med Res (2012) 43:514-21. doi: 10.1016/ j.arcmed.2012.09.007

13. Park EY, Chang E, Lee EJ, Lee HW, Kang HG, Chun KH, et al. Targeting of Mir34a-NOTCH1 Axis Reduced Breast Cancer Stemness and Chemoresistance. Cancer Res (2014) 74:7573-82. doi: 10.1158/0008-5472.CAN-14-1140

14. Zheng Y, Lv X, Wang X, Wang B, Shao X, Huang Y, et al. MiR-181b Promotes Chemoresistance in Breast Cancer by Regulating Bim Expression. Oncol Rep (2016) 35:683-90. doi: 10.3892/or.2015.4417

15. Zhao L, Wang Y, Jiang L, He M, Bai X, Yu L, et al. MiR-302a/B/C/D Cooperatively Sensitizes Breast Cancer Cells to Adriamycin via Suppressing P-Glycoprotein(P-Gp) by Targeting MAP/ERK Kinase Kinase 1 (MEKK1). J Exp Clin Cancer Res (2016) 35:25. doi: 10.1186/s13046-016-0300-8

16. Chen X, Wang YW, Gao P. SPIN1, Negatively Regulated by miR-148/152, Enhances Adriamycin Resistance via Upregulating Drug Metabolizing Enzymes and Transporter in Breast Cancer. J Exp Clin Cancer Res (2018) 37:100. doi: 10.1186/s13046-018-0748-9

17. Hu D, Li M, Su J, Miao K, Qiu X. Dual-Targeting of miR-124-3p and ABCC4 Promotes Sensitivity to Adriamycin in Breast Cancer Cells. Genet Test Mol Biomarkers (2019) 23:156-65. doi: 10.1089/gtmb.2018.0259

18. Bao L, Hazari S, Mehra S, Kaushal D, Moroz K, Dash S. Increased Expression of P-Glycoprotein and Doxorubicin Chemoresistance of Metastatic Breast Cancer is Regulated by miR-298. Am J Pathol (2012) 180:2490-503. doi: 10.1016/j.ajpath.2012.02.024

19. Shen H, Li L, Yang S, Wang D, Zhong S, Zhao J, et al. MicroRNA-29a Contributes to Drug-Resistance of Breast Cancer Cells to Adriamycin Through PTEN/AKT/GSK3beta Signaling Pathway. Gene (2016) 593:8490. doi: 10.1016/j.gene.2016.08.016
Supplementary Figure 5 | The pattern diagram of ncRNAs and Fluorouracil chemoresistance.

Supplementary Figure 6 | The pattern diagram of ncRNAs and Trastuzumab chemoresistance.

20. Miao Y, Zheng W, Li N, Su Z, Zhao L, Zhou H, et al. MicroRNA-130b Targets PTEN to Mediate Drug Resistance and Proliferation of Breast Cancer Cells via the PI3K/Akt Signaling Pathway. Sci Rep (2017) 7:41942. doi: $10.1038 /$ srep41942

21. Wang DD, Yang SJ, Chen X, Shen HY, Luo LJ, Zhang XH, et al. miR-222 Induces Adriamycin Resistance in Breast Cancer Through PTEN/Akt/p27(kip1) Pathway. Tumour Biol (2016) 37:15315-24. doi: 10.1007/s13277-016-5341-2

22. Gao M, Miao L, Liu M, Li C, Yu C, Yan H, et al. miR-145 Sensitizes Breast Cancer to Doxorubicin by Targeting Multidrug Resistance-Associated Protein-1. Oncotarget (2016) 7:59714-26. doi: 10.18632/oncotarget.10845

23. Jiang L, He D, Yang D, Chen Z, Pan Q, Mao A, et al. MiR-489 Regulates Chemoresistance in Breast Cancer via Epithelial Mesenchymal Transition Pathway. FEBS Lett (2014) 588:2009-15. doi: 10.1016/j.febslet.2014.04.024

24. Hu SH, Wang CH, Huang ZJ, Liu F, Xu CW, Li XL, et al. miR-760 Mediates Chemoresistance Through Inhibition of Epithelial Mesenchymal Transition in Breast Cancer Cells. Eur Rev Med Pharmacol Sci (2016) 20:5002-8.

25. Zhang Y, He Y, Lu LL, Zhou ZY, Wan NB, Li GP, et al. miRNA-192-5p Impacts the Sensitivity of Breast Cancer Cells to Doxorubicin via Targeting Peptidylprolyl Isomerase A. Kaohsiung J Med Sci (2019) 35:17-23. doi: 10.1002/kjm2.12004

26. Zhao R, Wu J, Jia W, Gong C, Yu F, Ren Z, et al. Plasma miR-221 as a Predictive Biomarker for Chemoresistance in Breast Cancer Patients Who Previously Received Neoadjuvant Chemotherapy. Onkologie (2011) 34:67580. doi: $10.1159 / 000334552$

27. Chang L, Hu Z, Zhou Z, Zhang H. Linc00518 Contributes to Multidrug Resistance Through Regulating the MiR-199a/MRP1 Axis in Breast Cancer. Cell Physiol Biochem (2018) 48:16-28. doi: 10.1159/000491659

28. Liang Y, Li Y, Song X, Zhang N, Sang Y, Zhang H, et al. Long Noncoding RNA LINP1 Acts as an Oncogene and Promotes Chemoresistance in Breast Cancer. Cancer Biol Ther (2018) 19:120-31. doi: 10.1080/15384047.2017.1394543

29. Yao N, Fu Y, Chen L, Liu Z, He J, Zhu Y, et al. Long non-Coding RNA NONHSAT101069 Promotes Epirubicin Resistance, Migration, and Invasion of Breast Cancer Cells Through NONHSAT101069/miR-129-5p/ Twist1 Axis. Oncogene (2019) 38:7216-33. doi: 10.1038/s41388-019-0904-5

30. Gooding AJ, Zhang B, Gunawardane L, Beard A, Valadkhan S, Schiemann WP. The IncRNA BORG Facilitates the Survival and Chemoresistance of Triple-Negative Breast Cancers. Oncogene (2019) 38:2020-41. doi: 10.1038/ s41388-018-0586-4

31. Chen Z, Pan T, Jiang D, Jin L, Geng Y, Feng X, et al. The lncRNA-GAS5/ miR-221-3p/DKK2 Axis Modulates ABCB1-Mediated Adriamycin Resistance of Breast Cancer via the Wnt/beta-Catenin Signaling Pathway. Mol Ther Nucleic Acids (2020) 19:1434-48. doi: 10.1016/j.omtn.2020.01.030

32. Chang M. Tamoxifen Resistance in Breast Cancer. Biomol Ther (Seoul) (2012) 20:256-67. doi: 10.4062/biomolther.2012.20.3.256

33. Shagufta, Ahmad I. Tamoxifen a Pioneering Drug: An Update on the Therapeutic Potential of Tamoxifen Derivatives. Eur J Med Chem (2018) 143:515-31. doi: 10.1016/j.ejmech.2017.11.056

34. Siegel RL, Miller KD, Jemal A. Cancer Statistics, 2016. CA Cancer J Clin (2016) 66:7-30. doi: 10.3322/caac.21332

35. Jensen EV, Jordan VC. The Estrogen Receptor: A Model for Molecular Medicine. Clin Cancer Res (2003) 9:1980-9.

36. Chen L, Linden HM, Anderson BO, Li CI. Trends in 5-Year Survival Rates Among Breast Cancer Patients by Hormone Receptor Status and Stage. Breast Cancer Res Treat (2014) 147:609-16. doi: 10.1007/s10549-014-3112-6

37. Elliott T, Sethi T. Integrins and Extracellular Matrix: A Novel Mechanism of Multidrug Resistance. Expert Rev Anticancer Ther (2002) 2:449-59. doi: 10.1586/14737140.2.4.449

38. Joshi T, Elias D, Stenvang J, Alves CL, Teng F, Lyng MB, et al. Integrative Analysis of miRNA and Gene Expression Reveals Regulatory Networks in Tamoxifen-Resistant Breast Cancer. Oncotarget (2016) 7(35):57239-53. doi 10.18632/oncotarget.11136 
39. Uhr K, Prager-van der Smissen WJC, Heine AAJ, Ozturk B, van Jaarsveld MTM, Boersma AWM, et al. MicroRNAs as Possible Indicators of Drug Sensitivity in Breast Cancer Cell Lines. PloS One (2019) 14:e0216400. doi: 10.1371/journal.pone.0216400

40. Zhang W, Xu J, Shi Y, Sun Q, Zhang Q, Guan X. The Novel Role of miRNAs for Tamoxifen Resistance in Human Breast Cancer. Cell Mol Life Sci (2015) 72(13):2575-84. doi: 10.1007/s00018-015-1887-1

41. Gao Y, Zhang W, Liu C, Li G. miR-200 Affects Tamoxifen Resistance in Breast Cancer Cells Through Regulation of MYB. Sci Rep (2019) 9:18844. doi: 10.1038/s41598-019-54289-6

42. Iijima M, Anai M, Kodama T, Shibasaki Y. Epiregulin-Blocking Antibody Inhibits Epiregulin-Dependent EGFR Signaling. Biochem Biophys Res Commun (2017) 489:83-8. doi: 10.1016/j.bbrc.2017.03.006

43. Farooqui M, Bohrer LR, Brady NJ, Chuntova P, Kemp SE, Wardwell CT, et al. Epiregulin Contributes to Breast Tumorigenesis Through Regulating Matrix Metalloproteinase 1 and Promoting Cell Survival. Mol Cancer (2015) 14:138. doi: 10.1186/s12943-015-0408-Z

44. He M, Jin Q, Chen C, Liu Y, Ye X, Jiang Y, et al. The miR-186-3p/EREG Axis Orchestrates Tamoxifen Resistance and Aerobic Glycolysis in Breast Cancer Cells. Oncogene (2019) 38:5551-65. doi: 10.1038/s41388-019-0817-3

45. Miller TE, Ghoshal K, Ramaswamy B, Roy S, Datta J, Shapiro CL, et al. MicroRNA221/222 Confers Tamoxifen Resistance in Breast Cancer by Targeting p27Kip1. J Biol Chem (2008) 283:29897-903. doi: 10.1074/jbc.M804612200

46. Li J, Lu M, Jin J, Lu X, Xu T, Jin S. miR-449a Suppresses Tamoxifen Resistance in Human Breast Cancer Cells by Targeting Adam22. Cell Physiol Biochem (2018) 50:136-49. doi: 10.1159/000493964

47. Liu ZR, Song Y, Wan LH, Zhang YY, Zhou LM. Over-Expression of miR451a can Enhance the Sensitivity of Breast Cancer Cells to Tamoxifen by Regulating 14-3-3zeta, Estrogen Receptor Alpha, and Autophagy. Life Sci (2016) 149:104-13. doi: 10.1016/j.lfs.2016.02.059

48. Liu Z, Miao T, Feng T, Jiang Z, Li M, Zhou L, et al. miR-451a Inhibited Cell Proliferation and Enhanced Tamoxifen Sensitive in Breast Cancer via Macrophage Migration Inhibitory Factor. BioMed Res Int (2015) 2015:207684. doi: 10.1155/2015/207684

49. Ye P, Fang C, Zeng H, Shi Y, Pan Z, An N, et al. Differential microRNA Expression Profiles in Tamoxifen-Resistant Human Breast Cancer Cell Lines Induced by Two Methods. Oncol Lett (2018) 15:3532-9. doi: 10.3892/ol.2018.7768

50. Fan C, Oh DS, Wessels L, Weigelt B, Nuyten DS, Nobel AB, et al. Concordance Among Gene-Expression-Based Predictors for Breast Cancer. N Engl J Med (2006) 355:560-9. doi: 10.1056/NEJMoa052933

51. Zhang X, Gao S, Li Z, Wang W, Liu G. Identification and Analysis of Estrogen Receptor $\alpha$ Promoting Tamoxifen Resistance-Related lncRNAs. BioMed Res Int (2020) 2020:9031723. doi: 10.1155/2020/9031723

52. Li Z, Yu D, Li H, Lv Y, Li S. Long non-Coding RNA UCA1 Confers Tamoxifen Resistance in Breast Cancer Endocrinotherapy Through Regulation of the EZH2/p21 Axis and the PI3K/AKT Signaling Pathway. Int J Oncol (2019) 54(3):1033-42. doi: 10.3892/ijo.2019.4679

53. Liu Y, Li M, Yu H, Piao H. IncRNA CYTOR Promotes Tamoxifen Resistance in Breast Cancer Cells via Sponging Mir-125a-5p. Int J Mol Med (2020) 45 (2):497-509.54. doi: 10.3892/ijmm.2019.4428

54. Xue X, Yang YA, Zhang A, Fong KW, Kim J, Song B, et al. LncRNA HOTAIR Enhances ER Signaling and Confers Tamoxifen Resistance in Breast Cancer. Oncogene (2016) 35:2746-55. doi: 10.1038/onc.2015.340

55. Ma T, Liang Y, Li Y, Song X, Zhang N, Li X, et al. LncRNA LINP1 Confers Tamoxifen Resistance and Negatively Regulated by ER Signaling in Breast Cancer. Cell Signal (2020) 68:109536. doi: 10.1016/j.cellsig.2020.109536

56. Kim CY, Oh JH, Lee JY, Kim MH. The LncRNA HOTAIRM1 Promotes Tamoxifen Resistance by Mediating HOXA1 Expression in ER+ Breast Cancer Cells. J Cancer (2020) 11(12):3416-23. doi: 10.7150/jca.38728

57. Shi Q, Li Y, Li S, Jin L, Lai H, Wu Y, et al. LncRNA DILA1 Inhibits Cyclin D1 Degradation and Contributes to Tamoxifen Resistance in Breast Cancer. Nat Commun (2020) 11(1):5513. doi: 10.1038/s41467-020-19349-w

58. Qu R, Hu C, Tang Y, Yu Q, Shi G. Long Non-Coding RNA BLACAT1 Induces Tamoxifen Resistance in Human Breast Cancer by Regulating miR-503/Bcl-2 Axis. Cancer Manag Res (2020) 12:1771-7. doi: 10.2147/CMAR.S239981

59. Ma Y, Bu D, Long J, Chai W, Dong J. LncRNA DSCAM-AS1 Acts as a Sponge of miR-137 to Enhance Tamoxifen Resistance in Breast Cancer. $J$ Cell Physiol (2019) 234(3):2880-94. doi: 10.1002/jcp.27105
60. Xu CG, Yang MF, Ren YQ, Wu CH, Wang LQ. Exosomes Mediated Transfer of IncRNA UCA1 Results in Increased Tamoxifen Resistance in Breast Cancer Cells. Eur Rev Med Pharmacol Sci (2016) 20:4362-8.

61. Liu H, Wang G, Yang L, Qu J, Yang Z, Zhou X. Knockdown of Long NonCoding RNA UCA1 Increases the Tamoxifen Sensitivity of Breast Cancer Cells Through Inhibition of Wnt/beta-Catenin Pathway. PloS One (2016) 11: e0168406. doi: 10.1371/journal.pone.0168406

62. Wu C, Luo J. Long Non-Coding RNA (lncRNA) Urothelial CarcinomaAssociated 1 (UCA1) Enhances Tamoxifen Resistance in Breast Cancer Cells via Inhibiting mTOR Signaling Pathway. Med Sci Monit (2016) 22:3860-7. doi: 10.12659/MSM.900689

63. Shi YF, Lu H, Wang HB. Downregulated lncRNA ADAMTS9-AS2 in Breast Cancer Enhances Tamoxifen Resistance by Activating microRNA-130a-5p. Eur Rev Med Pharmacol Sci (2019) 23(4):1563-73. doi: 10.26355/ eurrev_201902_17115

64. Zhang HY, Liang F, Zhang JW, Wang F, Wang L, Kang XG. Effects of Long Noncoding RNA-ROR on Tamoxifen Resistance of Breast Cancer Cells by Regulating microRNA-205. Cancer Chemother Pharmacol (2017) 79(2):32737. doi: 10.1007/s00280-016-3208-2

65. Chen LL, Yang L. Regulation of circRNA Biogenesis. RNA Biol (2015) 12 (4):381-8. doi: 10.1080/15476286.2015.1020271

66. Hansen TB, Jensen TI, Clausen BH, Bramsen JB, Finsen B, Damgaard C, et al. Natural RNA Circles Function as Efficient microRNA Sponges. Nature (2013) 495:384-8. doi: 10.1038/nature11993

67. Sang Y, Chen B, Song X, Li Y, Liang Y, Han D, et al. circRNA_0025202 Regulates Tamoxifen Sensitivity and Tumor Progression via Regulating the miR-182-5p/FOXO3a Axis in Breast Cancer. Mol Ther (2019) 27(9):163852. doi: 10.1016/j.ymthe.2019.05.011

68. Liang Y, Song X, Li Y, Ma T, Su P, Guo R, et al. Targeting the Circbmpr2/ miR-553/USP4 Axis as a Potent Therapeutic Approach for Breast Cancer. Mol Ther Nucleic Acids (2019) 17:347-61. doi: 10.1016/j.omtn.2019.05.005

69. Hu K, Liu X, Li Y, Li Q, Xu Y, Zeng W, et al. Exosomes Mediated Transfer of Circ_UBE2D2 Enhances the Resistance of Breast Cancer to Tamoxifen by Binding to MiR-200a-3p. Med Sci Monit (2020) 26:e922253. doi: 10.12659/MSM.922253

70. Uhr K, Sieuwerts AM, de Weerd V, Smid M, Hammerl D, Foekens JA, et al. Association of microRNA-7 and its Binding Partner CDR1-AS With the Prognosis and Prediction of 1st-Line Tamoxifen Therapy in Breast Cancer. Sci Rep (2018) 8(1):9657-65. doi: 10.1038/s41598-018-27987-w

71. Picard M. Management of Hypersensitivity Reactions to Taxanes. Immunol Allergy Clin North Am (2017) 37:679-93. doi: 10.1016/j.iac.2017.07.004

72. Sparano JA. Taxanes for Breast Cancer: An Evidence-Based Review of Randomized Phase II and Phase III Trials. Clin Breast Cancer (2000) 1:32-40; discussion 41-32. doi: 10.3816/CBC.2000.n.002

73. Perou CM, Sorlie T, Eisen MB, van de Rijn M, Jeffrey SS, Rees CA, et al. Molecular Portraits of Human Breast Tumours. Nature (2000) 406:747-52. doi: $10.1038 / 35021093$

74. Prat A, Parker JS, Karginova O, Fan C, Livasy C, Herschkowitz JI, et al. Phenotypic and Molecular Characterization of the Claudin-Low Intrinsic Subtype of Breast Cancer. Breast Cancer Res (2010) 12:R68. doi: 10.1186/bcr2635

75. Yu KD, Zhu R, Zhan M, Rodriguez AA, Yang W, Wong S, et al. Identification of Prognosis-Relevant Subgroups in Patients With Chemoresistant Triple-Negative Breast Cancer. Clin Cancer Res (2013) 19:2723-33. doi: 10.1158/1078-0432.CCR-12-2986

76. Bonnefoi H, Piccart M, Bogaerts J, Mauriac L, Fumoleau P, Brain E, et al. TP53 Status for Prediction of Sensitivity to Taxane Versus non-Taxane Neoadjuvant Chemotherapy in Breast Cancer (EORTC 10994/BIG 1-00): A Randomised Phase 3 Trial. Lancet Oncol (2011) 12:527-39. doi: 10.1016/ S1470-2045(11)70094-8

77. Teng R, Hu Y, Zhou J, Seifer B, Chen Y, Shen J, et al. Overexpression of Lin28 Decreases the Chemosensitivity of Gastric Cancer Cells to Oxaliplatin, Paclitaxel, Doxorubicin, and Fluorouracil in Part via microRNA-107. PloS One (2015) 10:e0143716. doi: 10.1371/journal.pone.0143716

78. Lv K, Liu L, Lm W, Yu J, Liu X, Cheng Y, et al. Lin28 Mediates Paclitaxel Resistance by Modulating P21, Rb and Let-7a miRNA in Breast Cancer Cells. PloS One (2012) 7:e40008. doi: 10.1371/journal.pone.0040008

79. Tsang WP, Kwok TT. Let-7a microRNA Suppresses Therapeutics-Induced Cancer Cell Death by Targeting Caspase-3. Apoptosis (2008) 13:1215-22. doi: 10.1007/s10495-008-0256-z 
80. Tao WY, Liang XS, Liu Y, Wang CY, Pang D. Decrease of Let-7f in LowDose Metronomic Paclitaxel Chemotherapy Contributed to Upregulation of Thrombospondin-1 in Breast Cancer. Int J Biol Sci (2015) 11:48-58. doi: 10.7150/ijbs. 9969

81. Zhou M, Liu Z, Zhao Y, Ding Y, Liu H, Xi Y, et al. MicroRNA-125b Confers the Resistance of Breast Cancer Cells to Paclitaxel Through Suppression of Pro-Apoptotic Bcl-2 Antagonist Killer 1 (Bak1) Expression. J Biol Chem (2010) 285:21496-507. doi: 10.1074/jbc.M109.083337

82. Su CM, Wang MY, Hong CC, Chen HA, Su YH, Wu CH, et al. miR-520h is Crucial for DAPK2 Regulation and Breast Cancer Progression. Oncogene (2016) 35:1134-42. doi: 10.1038/onc.2015.168

83. Gu X, Li JY, Guo J, Li PS, Zhang WH. Influence of MiR-451 on Drug Resistances of Paclitaxel-Resistant Breast Cancer Cell Line. Med Sci Monit (2015) 21:3291-7. doi: 10.12659/MSM.894475

84. Guo L, Chen G, Zhang W, Zhou L, Xiao T, Di X, et al. A High-Risk Luminal A Dominant Breast Cancer Subtype With Increased Mobility. Breast Cancer Res Treat (2019) 175(2):459-72. doi: 10.1007/s10549-019-05135-w

85. Zhang B, Zhao R, He Y, Fu X, Fu L, Zhu Z, et al. MicroRNA 100 Sensitizes Luminal A Breast Cancer Cells to Paclitaxel Treatment in Part by Targeting mTOR. Oncotarget (2016) 7:5702-14. doi: 10.18632/oncotarget.6790

86. Sha LY, Zhang Y, Wang W, Sui X, Liu SK, Wang T, et al. MiR-18a Upregulation Decreases Dicer Expression and Confers Paclitaxel Resistance in Triple Negative Breast Cancer. Eur Rev Med Pharmacol Sci (2016) 20:2201-8.

87. Liu X, Tang H, Chen J, Song C, Yang L, Liu P, et al. M.A-101 Inhibits Cell Progression and Increases Paclitaxel Sensitivity by Suppressing MCL-1 Expression in Human Triple-Negative Breast Cancer. Oncotarget (2015) 6:20070-83. doi: 10.18632/oncotarget.4039

88. Arun G, Spector DL. MALAT1 Long non-Coding RNA and Breast Cancer. RNA Biol (2019) 16:860-3. doi: 10.1080/15476286.2019.1592072

89. Yu J, Jin T, Zhang T. Suppression of Long Non-Coding RNA MetastasisAssociated Lung Adenocarcinoma Transcript 1 (MALAT1) Potentiates Cell Apoptosis and Drug Sensitivity to Taxanes and Adriamycin in Breast Cancer. Med Sci Monit (2020) 26:e922672. doi: 10.12659/MSM.922672

90. Zheng P, Dong L, Zhang B, Dai J, Zhang Y, Wang Y, et al. Long Noncoding RNA CASC2 Promotes Paclitaxel Resistance in Breast Cancer Through Regulation of miR-18a-5p/CDK19. Histochem Cell Biol (2019) 152:281-91. doi: 10.1007/s00418-019-01794-4

91. Yao H, He G, Yan S, Chen C, Song L, Rosol TJ, et al. Triple-Negative Breast Cancer: Is There a Treatment on the Horizon? Oncotarget (2017) 8:1913-24. doi: 10.18632/oncotarget.12284

92. Si X, Zang R, Zhang E, Liu Y, Shi X, Zhang E, et al. LncRNA H19 Confers Chemoresistance in Ero-Positive Breast Cancer Through Epigenetic Silencing of the Pro-Apoptotic Gene BIK. Oncotarget (2016) 7(49):8145262. doi: $10.18632 /$ oncotarget. 13263

93. Raveh E, Matouk IJ, Gilon M, Hochberg A. The H19 Long non-Coding RNA in Cancer Initiation, Progression and Metastasis - a Proposed Unifying Theory. Mol Cancer (2015) 14:184. doi: 10.1186/s12943-015-0458-2

94. Han J, Han B, Wu X, Hao J, Dong X, Shen Q, et al. Knockdown of IncRNA H19 Restores Chemo-Sensitivity in Paclitaxel-Resistant Triple-Negative Breast Cancer Through Triggering Apoptosis and Regulating Akt Signaling Pathway. Toxicol Appl Pharmacol (2018) 359:55-61. doi: 10.1016/j.taap.2018.09.018

95. Chen Q, Shen H, Zhu X, Liu Y, Yang H, Chen H, et al. A Nuclear IncRNA Linc00839 as a Myc Target to Promote Breast Cancer Chemoresistance via PI3K/ AKT Signaling Pathway. Cancer Sci (2020) 111:3279-91. doi: 10.1111/cas.14555

96. Ma J, Fang L, Yang Q, Hibberd S, Du WW, Wu N, et al. Posttranscriptional Regulation of AKT by Circular RNA Angiomotin- Like 1 Mediates Chemoresistance Against Paclitaxel in Breast Cancer Cells. Aging (Albany NY) (2019) 11:11369-81. doi: 10.18632/aging.102535

97. Yang W, Gong P, Yang Y, Yang C, Yang B, Ren L. Circ-ABCB10 Contributes to Paclitaxel Resistance in Breast Cancer Through Let-7a-5p/DUSP7 Axis. Cancer Manag Res (2020) 12:2327-37. doi: 10.2147/CMAR.S238513

98. Zang H, Li Y, Zhang X, Huang G. Circ-RNF111 Contributes to Paclitaxel Resistance in Breast Cancer by Elevating E2F3 Expression via miR-140-5p. Thorac Cancer (2020) 11:1891-903. doi: 10.1111/1759-7714.13475

99. Nabholtz JM, Gligorov J. Docetaxel in the Treatment of Breast Cancer: Current Experience and Future Prospects. Expert Rev Anticancer Ther (2005) 5:613-33. doi: 10.1586/14737140.5.4.613
100. Jones SE, Erban J, Overmoyer B, Budd GT, Hutchins L, Lower E, et al. Randomized Phase III Study of Docetaxel Compared With Paclitaxel in Metastatic Breast Cancer. J Clin Oncol (2005) 23:5542-51. doi: 10.1200/ JCO.2005.02.027

101. Qi WX, Shen Z, Lin F, Sun YJ, Min DL, Tang LN, et al. Paclitaxel-Based Versus Docetaxel-Based Regimens in Metastatic Breast Cancer: A Systematic Review and Meta-Analysis of Randomized Controlled Trials. Curr Med Res Opin (2013) 29:117-25. doi: 10.1185/03007995.2012.756393

102. Yao YS, Qiu WS, Yao RY, Zhang Q, Zhuang LK, Zhou F, et al. miR-141 Confers Docetaxel Chemoresistance of Breast Cancer Cells via Regulation of EIF4E Expression. Oncol Rep (2015) 33:2504-12. doi: 10.3892/or.2015.3866

103. Zhang Y, Wang Y, Wei Y, Li M, Yu S, Ye M, et al. MiR-129-3p Promotes Docetaxel Resistance of Breast Cancer Cells via CP110 Inhibition. Sci Rep (2015) 5:15424. doi: 10.1038/srep15424

104. Zhang X, Zhong S, Xu Y, Yu D, Ma T, Chen L, et al. MicroRNA-3646 Contributes to Docetaxel Resistance in Human Breast Cancer Cells by GSK3beta/Beta-Catenin Signaling Pathway. PloS One (2016) 11:e0153194. doi: 10.1371/journal.pone.0153194

105. Hu Q, Chen WX, Zhong SL, Zhang JY, Ma TF, Ji H, et al. MicroRNA-452 Contributes to the Docetaxel Resistance of Breast Cancer Cells. Tumour Biol (2014) 35:6327-34. doi: 10.1007/s13277-014-1834-Z

106. Hu H, Li S, Cui X, Lv X, Jiao Y, Yu F, et al. The Overexpression of Hypomethylated miR-663 Induces Chemotherapy Resistance in Human Breast Cancer Cells by Targeting Heparin Sulfate Proteoglycan 2 (HSPG2). J Biol Chem (2013) 288:10973-85. doi: 10.1074/jbc.M112.434340

107. Kastl L, Brown I, Schofield AC. miRNA-34a is Associated With Docetaxel Resistance in Human Breast Cancer Cells. Breast Cancer Res Treat (2012) 131:445-54. doi: 10.1007/s10549-011-1424-3

108. Zhang HD, Sun DW, Mao L, Zhang J, Jiang LH, Li J, et al. MiR-139-5p Inhibits the Biological Function of Breast Cancer Cells by Targeting Notch1 and Mediates Chemosensitivity to Docetaxel. Biochem Biophys Res Commun (2015) 465:702-13. doi: 10.1016/j.bbrc.2015.08.053

109. Cai Y, Yan X, Zhang G, Zhao W, Jiao S. MicroRNA-205 Increases the Sensitivity of Docetaxel in Breast Cancer. Oncol Lett (2016) 11:1105-9. doi: 10.3892/ol.2015.4030

110. Xu X, Lv YG, Yan CY, Yi J, Ling R. Enforced Expression of hsa-miR-125a-3p in Breast Cancer Cells Potentiates Docetaxel Sensitivity via Modulation of BRCA1 Signaling. Biochem Biophys Res Commun (2016) 479:893-900. doi: 10.1016/j.bbrc.2016.09.087

111. Zhong S, Li W, Chen Z, Xu J, Zhao J. MiR-222 and miR-29a Contribute to the Drug-Resistance of Breast Cancer Cells. Gene (2013) 531:8-14. doi: 10.1016/j.gene.2013.08.062

112. Chen WX, Cai YQ, Lv MM, Chen L, Zhong SL, Ma TF, et al. Exosomes From Docetaxel-Resistant Breast Cancer Cells Alter Chemosensitivity by Delivering microRNAs. Tumour Biol (2014) 35:9649-59. doi: 10.1007/s13277-014-2242-0

113. Huang P, Li F, Li L, You Y, Luo S, Dong Z, et al. IncRNA Profile Study Reveals the mRNAs and lncRNAs Associated With Docetaxel Resistance in Breast Cancer Cells. Sci Rep (2018) 8:17970. doi: 10.1038/s41598-018-36231-4

114. Shin VY, Chen J, Cheuk IW, Siu MT, Ho CW, Wang X, et al. Long nonCoding RNA NEAT1 Confers Oncogenic Role in Triple-Negative Breast Cancer Through Modulating Chemoresistance and Cancer Stemness. Cell Death Dis (2019) 10:270. doi: 10.1038/s41419-019-1513-5

115. Wei Y, Yang P, Cao S, Zhao L. The Combination of Curcumin and 5Fluorouracil in Cancer Therapy. Arch Pharm Res (2018) 41(1):1-13. doi: 10.1007/s12272-017-0979-x

116. Zhang W, Feng M, Zheng G, Chen Y, Wang X, Pen B, et al. Chemoresistance to 5-Fluorouracil Induces Epithelial-Mesenchymal Transition via UpRegulation of Snail in MCF7 Human Breast Cancer Cells. Biochem Biophys Res Commun (2012) 417:679-85. doi: 10.1016/j.bbrc.2011.11.142

117. Deng J, Wang Y, Lei J, Lei W, Xiong JP. Insights Into the Involvement of Noncoding RNAs in 5-Fluorouracil Drug Resistance. Tumour Biol (2017) 39 (4):1-10. doi: 10.1177/1010428317697553

118. Nandy SB, Arumugam A, Subramani R, Pedroza D, Hernandez K, Saltzstein E, et al. MicroRNA-125a Influences Breast Cancer Stem Cells by Targeting Leukemia Inhibitory Factor Receptor Which Regulates the Hippo Signaling Pathway. Oncotarget (2015) 6:17366-78. doi: 10.18632/oncotarget.3953

119. Zhang Y, Qu X, Teng Y, Li Z, Xu L, Liu J, et al. Cbl-B Inhibits P-Gp Transporter Function by Preventing its Translocation Into Caveolae in 
Multiple Drug-Resistant Gastric and Breast Cancers. Oncotarget (2015) 6:6737-48. doi: 10.18632/oncotarget.3253

120. Yin J, Zheng G, Jia X, Zhang Z, Zhang W, Song Y, et al. A Bmil-miRNAs Cross-Talk Modulates Chemotherapy Response to 5-Fluorouracil in Breast Cancer Cells. PloS One (2013) 8:e73268. doi: 10.1371/journal.pone.0073268

121. Li QQ, Chen ZQ, Cao XX, Xu JD, Xu JW, Chen YY, et al. Involvement of NFKappab/miR-448 Regulatory Feedback Loop in Chemotherapy-Induced Epithelial-Mesenchymal Transition of Breast Cancer Cells. Cell Death Differ (2011) 18:16-25. doi: 10.1038/cdd.2010.103

122. Redis RS, Sieuwerts AM, Look MP, Tudoran O, Ivan C, Spizzo R, et al. CCAT2, a Novel Long non-Coding RNA in Breast Cancer: Expression Study and Clinical Correlations. Oncotarget (2013) 4:1748-62. doi: 10.18632/oncotarget.1292

123. Li X, Wang S, Li Z, Long X, Guo Z, Zhang G, et al. The IncRNA NEAT1 Facilitates Cell Growth and Invasion via the miR-211/HMGA2 Axis in Breast Cancer. Int $J$ Biol Macromol (2017) 105:346-53. doi: 10.1016/j.ijbiomac.2017.07.053

124. Chen YM, Liu Y, Wei HY, Lv KZ, Fu P. Lnc-ROR Induces Epithelial-Mesenchymal Transition and Contributes to Drug Resistance and Invasion of Breast Cancer Cells. Tumour Biol (2016) 37:10861-70. doi: 10.1007/s13277-016-4909-1

125. Hou P, Zhao Y, Li Z, Yao R, Ma M, Gao Y, et al. LncRNA-ROR Induces Epithelial-to-Mesenchymal Transition and Contributes to Breast Cancer Tumorigenesis and Metastasis. Cell Death Dis (2014) 5:e1287. doi: 10.1038/ cddis.2014.249

126. Yao XL, Yi T, Xu YL, Guo XY, Yao F, Zhang XH. Endoplasmic Reticulum Stress Confers 5-Fluorouracil Resistance in Breast Cancer Cell via the GRP78/OCT4/ IncRNA MIAT/AKT Pathway. Am J Cancer Res (2020) 10(3):838-55.

127. Luo L, Zhang J, Tang H, Zhai D, Huang D, Ling L, et al. LncRNA SNORD3A Specifically Sensitizes Breast Cancer Cells to 5-FU by Sponging miR-185-5p to Enhance UMPS Expression. Cell Death Dis (2020) 11:329. doi: 10.1038/ s41419-020-2557-2

128. Zhu J, Zhang X, Gao W, Hu H, Wang X, Hao D. IncRNA/ circRNA- miRNAmRNA ceRNA Network in Lumbar Intervertebral Disc Degeneration. Mol Med Rep (2019) 20(4):3160-74. doi: 10.3892/mmr.2019.10569

129. Yang W, Gu J, Wang X, Wang Y, Feng M, Zhou D, et al. Inhibition of Circular RNA CDRlas Increases Chemosensitivity of 5-FU-Resistant BC Cells Through Up-Regulating miR-7. J Cell Mol Med (2019) 23:3166-77. doi: $10.1111 / \mathrm{jcmm} .14171$

130. Cobleigh MA, Vogel CL, Tripathy D, Robert NJ, Scholl S, Fehrenbacher L, et al. Multinational Study of the Efficacy and Safety of Humanized Anti-HER2 Monoclonal Antibody in Women Who Have HER2-Overexpressing Metastatic Breast Cancer That has Progressed After Chemotherapy for Metastatic Disease. J Clin Oncol (1999) 17:2639-48. doi: 10.1200/JCO.1999.17.9.2639

131. Marty M, Cognetti F, Maraninchi D, Snyder R, Mauriac L, Tubiana-Hulin M, et al. Randomized Phase II Trial of the Efficacy and Safety of Trastuzumab Combined With Docetaxel in Patients With Human Epidermal Growth Factor Receptor 2-Positive Metastatic Breast Cancer Administered as FirstLine Treatment: The M77001 Study Group. J Clin Oncol (2005) 23:4265-74. doi: $10.1200 / \mathrm{JCO} .2005 .04 .173$

132. Esteva FJ, Valero V, Booser D, Guerra LT, Murray JL, Pusztai L, et al. Phase II Study of Weekly Docetaxel and Trastuzumab for Patients With HER-2Overexpressing Metastatic Breast Cancer. J Clin Oncol (2002) 20:1800-8. doi: 10.1200/JCO.2002.07.058

133. Deepti T, Amit SY, Dhiraj K, Garima B, Gopal CK. Non-Coding RNAs as Potential Therapeutic Targets in Breast Cancer. Biochim Biophys Acta Gene Regul Mech (2020) 1863(4):194378. doi: 10.1016/j.bbagrm.2019.04.005

134. Gong C, Yao Y, Wang Y, Liu B, Wu W, Chen J, et al. Up-Regulation of miR21 Mediates Resistance to Trastuzumab Therapy for Breast Cancer. J Biol Chem (2011) 286:19127-37. doi: 10.1074/jbc.M110.216887

135. De Mattos Arruda L, Bottai G, Nuciforo PG, Di TL, Giovannetti E, Peg V, et al. MicroRNA-21 Links Epithelial-to-Mesenchymal Transition and Inflammatory Signals to Confer Resistance to Neoadjuvant Trastuzumab and Chemotherapy in HER2-Positive Breast Cancer Patients. Oncotarget (2015) 6:37269-80. doi: 10.18632/oncotarget.5495

136. Nielsen BS, Balslev E, Poulsen TS, Nielsen D, Moller T, Mortensen CE, et al. miR-21 Expression in Cancer Cells may Not Predict Resistance to Adjuvant Trastuzumab in Primary Breast Cancer. Front Oncol (2014) 4:207. doi: 10.3389/fonc.2014.00207

137. Ye X, Bai W, Zhu H, Zhang X, Chen Y, Wang L, et al. MiR-221 Promotes Trastuzumab-Resistance and Metastasis in HER2-Positive Breast Cancers by
Targeting PTEN. BMB Rep (2014) 47:268-73. doi: 10.5483/BMBRep.2014. 47.5.165

138. Jung EJ, Santarpia L, Kim J, Esteva FJ, Moretti E, Buzdar AU, et al. Plasma microRNA 210 Levels Correlate With Sensitivity to Trastuzumab and Tumor Presence in Breast Cancer Patients. Cancer (2012) 118:2603-14. doi: $10.1002 / \mathrm{cncr} .26565$

139. Bai WD, Ye XM, Zhang MY, Zhu HY, Xi WJ, Huang X, et al. MiR-200c Suppresses TGF-Beta Signaling and Counteracts Trastuzumab Resistance and Metastasis by Targeting ZNF217 and ZEB1 in Breast Cancer. Int J Cancer (2014) 135:1356-68. doi: 10.1002/ijc.28782

140. Ye XM, Zhu HY, Bai WD, Wang T, Wang L, Chen Y, et al. Epigenetic Silencing of miR-375 Induces Trastuzumab Resistance in HER2-Positive Breast Cancer by Targeting IGF1R. BMC Cancer (2014) 14:134. doi: 10.1186/ 1471-2407-14-134

141. Ma T, Yang L, Zhang J. MiRNA5423p Downregulation Promotes Trastuzumab Resistance in Breast Cancer Cells via AKT Activation. Oncol Rep (2015) 33:1215-20. doi: 10.3892/or.2015.3713

142. Corcoran C, Rani S, Breslin S, Gogarty M, Ghobrial IM, Crown J, et al. miR630 Targets IGF1R to Regulate Response to HER-Targeting Drugs and Overall Cancer Cell Progression in HER2 Over-Expressing Breast Cancer. Mol Cancer (2014) 13:71. doi: 10.1186/1476-4598-13-71

143. Venturutti L, Cordo Russo RI, Rivas MA, Mercogliano MF, Izzo F, Oakley RH, et al. MiR-16 Mediates Trastuzumab and Lapatinib Response in ErbB-2Positive Breast and Gastric Cancer via its Novel Targets CCNJ and FUBP1. Oncogene (2016) 35:6189-202. doi: 10.1038/onc.2016.151

144. Huynh FC, Jones FE. MicroRNA-7 Inhibits Multiple Oncogenic Pathways to Suppress HER2Delta16 Mediated Breast Tumorigenesis and Reverse Trastuzumab Resistance. PloS One (2014) 9:1-16. doi: 10.1371/ journal.pone.0114419

145. von Minckwitz G, Huang CS, Mano MS, Loibl S, Mamounas EP, Untch M, et al. Trastuzumab Emtansine for Residual Invasive HER2-Positive Breast Cancer. N Engl J Med (2019) 380:617-28. doi: 10.1056/NEJMoa1814017

146. Dong H, Wang W, Chen R, Zhang Y, Zou K, Ye M, et al. Exosome-Mediated Transfer of Lncrnasnhg14 Promotes Trastuzumab Chemoresistance in Breast Cancer. Int J Oncol (2018) 53:1013-26. doi: 10.3892/ijo.2018.4467

147. Dong H, Wang W, Mo S, Chen R, Zou K, Han J, et al. SP1-Induced lncRNA AGAP2-AS1 Expression Promotes Chemoresistance of Breast Cancer by Epigenetic Regulation of Myd88. J Exp Clin Cancer Res (2018) 37:202-17. doi: 10.1186/s13046-018-0875-3

148. Shi SJ, Wang LJ, Yu B, Li YH, Jin Y, Bai XZ. LncRNA-ATB Promotes Trastuzumab Resistance and Invasion-Metastasis Cascade in Breast Cancer. Oncotarget (2015) 6:11652-63. doi: 10.18632/oncotarget.3457

149. Li W, Zhai L, Wang H, Liu C, Zhang J, Chen W. Downregulation of LncRNA GAS5 Causes Trastuzumab Resistance in Breast Cancer. Oncotarget (2016) 7:27778-86. doi: 10.18632/oncotarget.8413

150. Han M, Qian X, Cao H, Wang F, Li X, Han N, et al. IncRNA ZNF649-AS1 Induces Trastuzumab Resistance by Promoting ATG5 Expression and Autophagy. Mol Ther (2020) 28(11):2488-502. doi: 10.1016/j.ymthe.2020.07.019

151. Chen T, Liu Z, Zeng W, Huang T. Down-Regulation of Long non-Coding RNA HOTAIR Sensitizes Breast Cancer to Trastuzumab. Sci Rep (2019) 9:19881-9. doi: 10.1038/s41598-019-53699-w

Conflict of Interest: The authors declare that the research was conducted in the absence of any commercial or financial relationships that could be construed as a potential conflict of interest.

Publisher's Note: All claims expressed in this article are solely those of the authors and do not necessarily represent those of their affiliated organizations, or those of the publisher, the editors and the reviewers. Any product that may be evaluated in this article, or claim that may be made by its manufacturer, is not guaranteed or endorsed by the publisher.

Copyright (c) 2021 Tian, Liu, Yu, Wu and Wang. This is an open-access article distributed under the terms of the Creative Commons Attribution License (CC BY). The use, distribution or reproduction in other forums is permitted, provided the original author(s) and the copyright owner(s) are credited and that the original publication in this journal is cited, in accordance with accepted academic practice. No use, distribution or reproduction is permitted which does not comply with these terms. 